
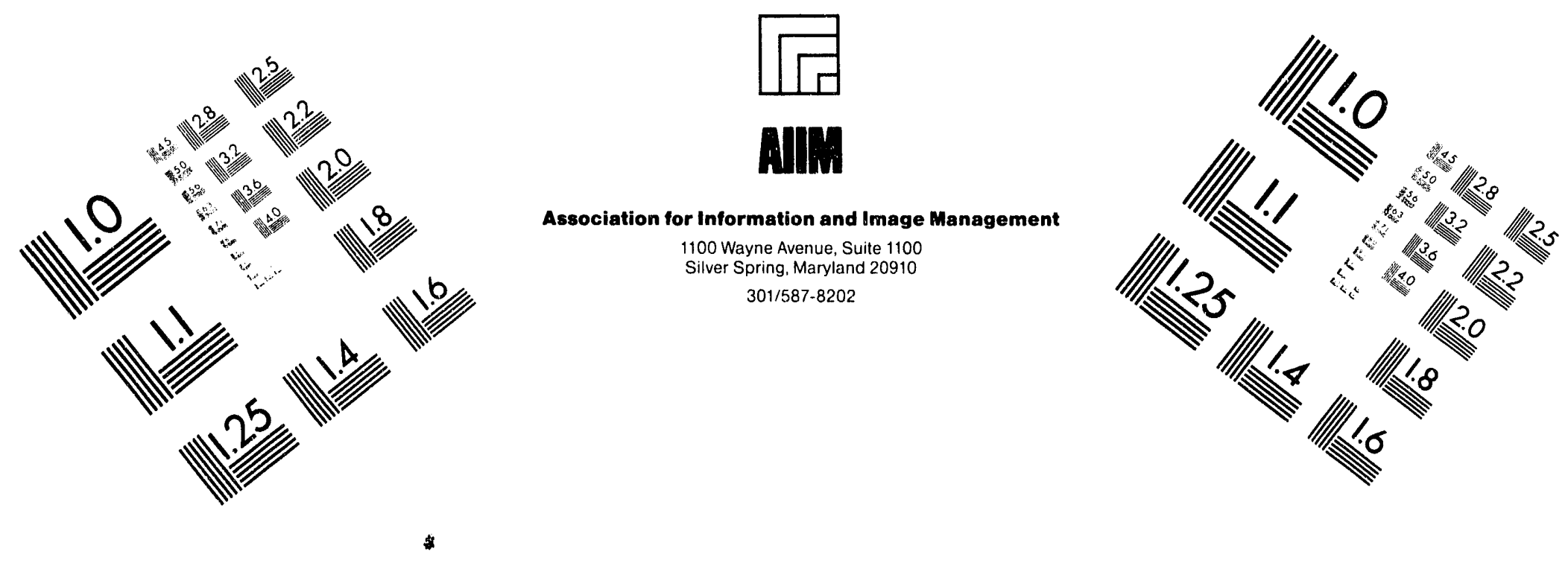

\title{
Centimeter
}

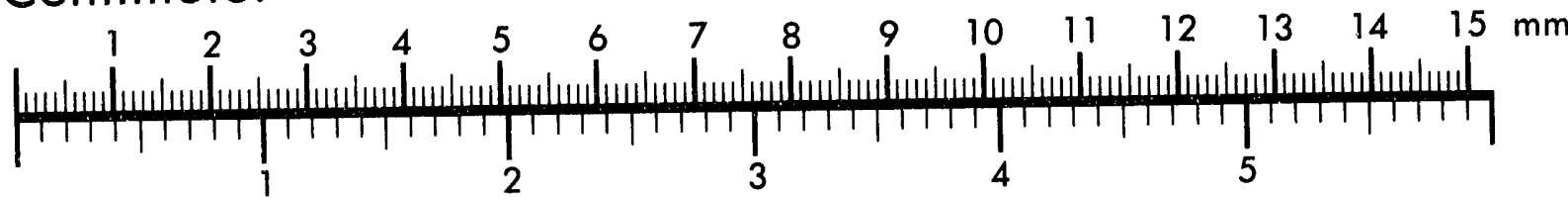

Inches
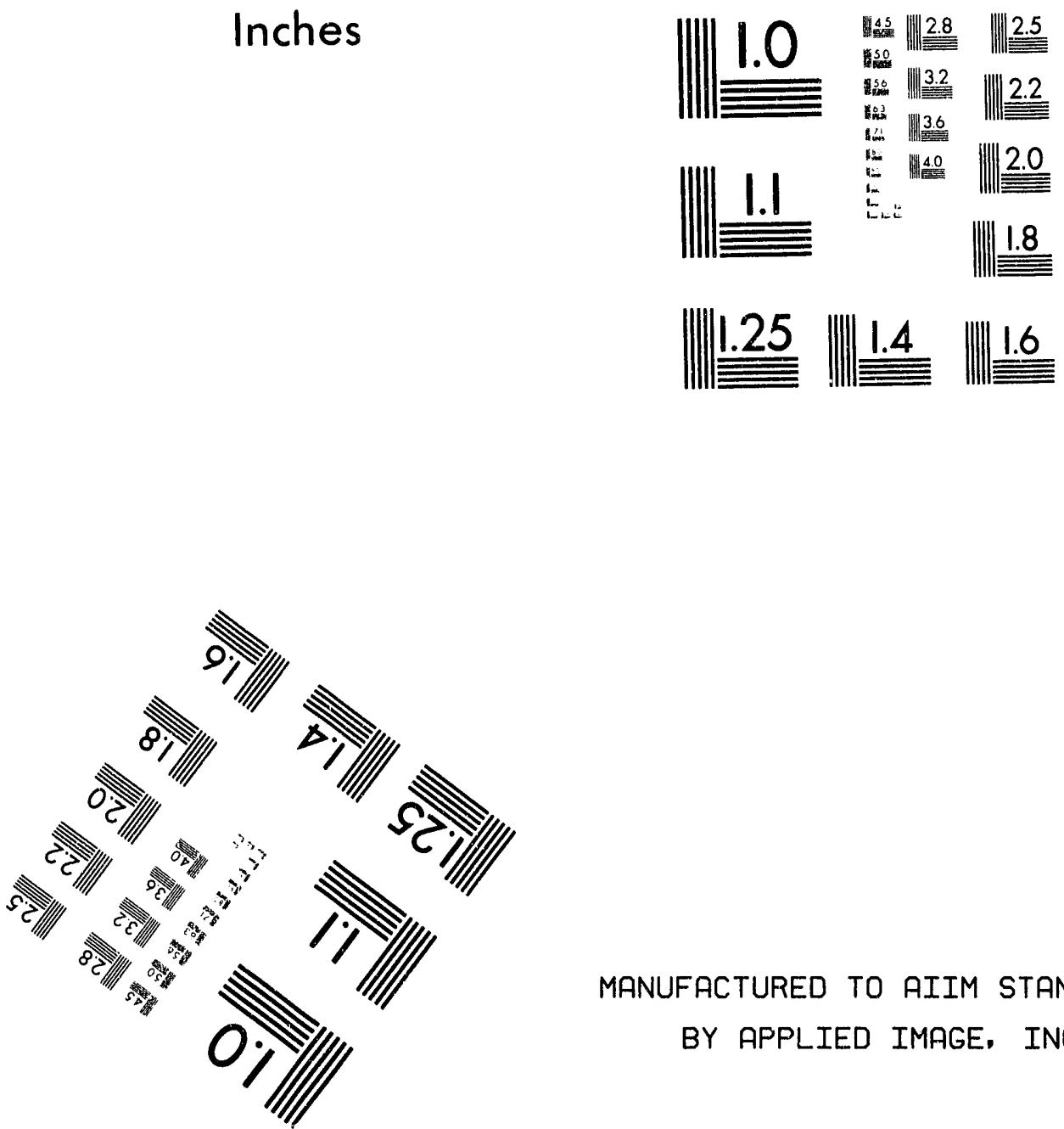

MANUFACTURED TO AIIM STANDARDS

BY APPLIED IMAGE, INC.

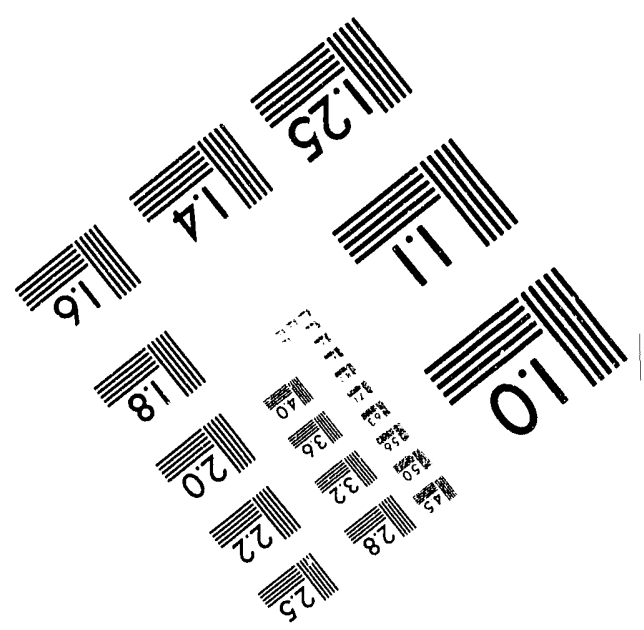



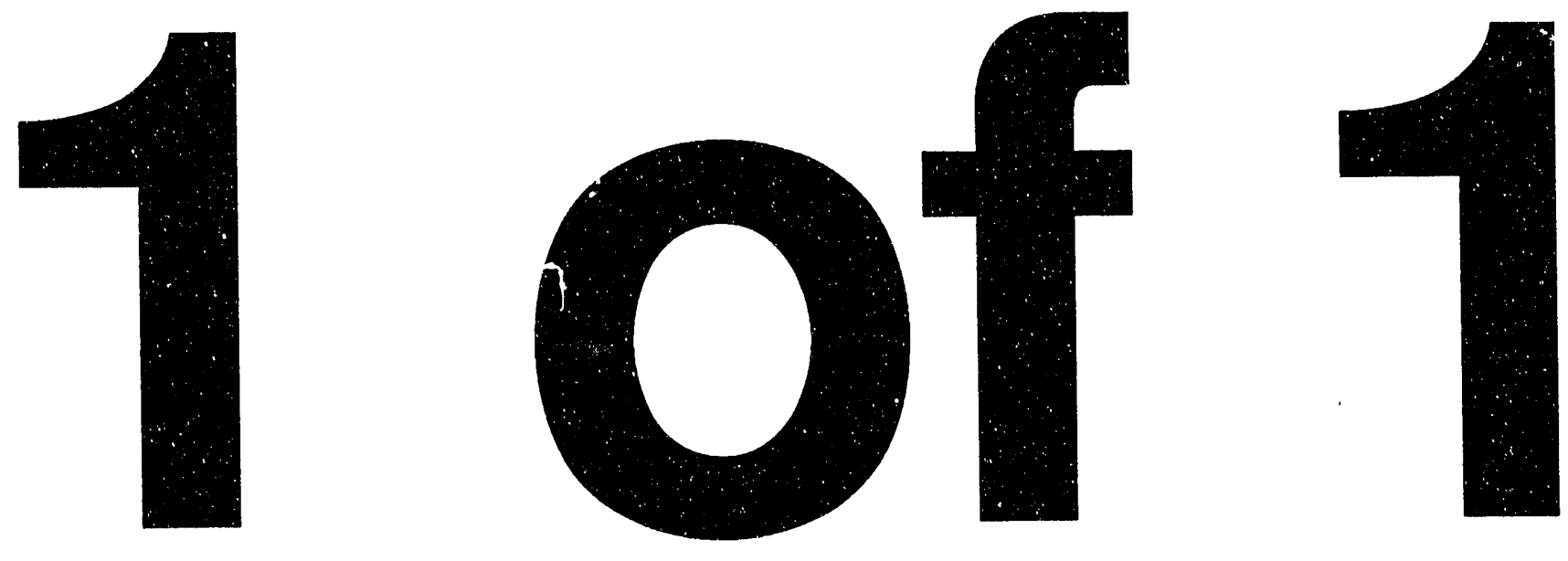


\section{A Study of the Compliance of the Gaseous Effluent Sampling and Monitoring System with Interim Criteria-296-B-10 Stack, Waste Encapsulation and Storage Facilitity}

February 1976 


\title{
A STUDY OF THE COMPLIANCE OF THE GASEOUS EFFLUENT SAHPLING AND MONITORING SYSTEM WITH INTERIM CRITERIA -- 296-B-10 STACK, WASTE ENCAPSULATION AND STORAGE FACILITY
}

\author{
L.C. SCHWENDIMAN \\ J.A. GLISSMEYER
}

Particulate \& Gaseous Waste Research ATMOSPHERIC SCIENCES DEPARTMEMT

FEBRUARY, 1976

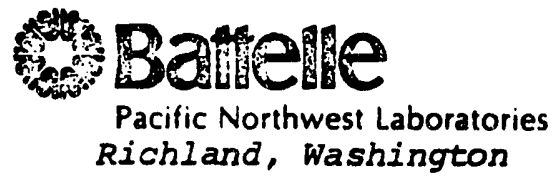


TABLE OF CONTENTS

\begin{tabular}{|c|c|}
\hline INTRODUCTION & 1 \\
\hline OBJECTIVE & 2 \\
\hline SUMMARY & 2 \\
\hline INTERPRETATION OF CRITERIA & 3 \\
\hline SAMPIING CRITERIA & 4 \\
\hline SAMPLING CRITERIA SUMMARY & 12 \\
\hline MONITORING CRITERIA & 14 \\
\hline $\begin{array}{l}\text { DESCRIPTION OF EXISTING GASEOUS EFFLUENT SAM- } \\
\text { PIING AND MONITORING SYSTEM AT THE } 296-\mathrm{B}-10 \text { STACK }\end{array}$ & 17 \\
\hline$K-1$ AND $K-3$ VENTILATION SYSTEMS & 17 \\
\hline SAMPLE COLLECTION SYSTEM & 17 \\
\hline MONITORING SYSTEM & 23 \\
\hline $\begin{array}{l}\text { EVALUATION OF THE COMPLIANCE OF THE SAMPIE } \\
\text { COLLECWION SYSTEM WITH THE INTERIM CRITERIA }\end{array}$ & 27 \\
\hline SAMPLE ALIQUOT SELECTION & 27 \\
\hline SAMPLE SYSTEM PERFORMANCE & 29 \\
\hline OTHER CRITERIA COMPLIANCE & 34 \\
\hline $\begin{array}{l}\text { EVALUATION OF THE COMPLIANCE OF THE MON- } \\
\text { ITORING SYSTEM WITH THE INTERIM CRITERIA }\end{array}$ & 35 \\
\hline SENSITIVITY AND CHOICE OF DETECTORS & 35 \\
\hline OPERATION OF MONITORING INSTRUMENTATION & 36 \\
\hline RECOMMENDATIONS & 37 \\
\hline SAMPLE COLLECTION SYSTEM & 38 \\
\hline RADIOACTIVITY DETECTION SYSTEMS & 39 \\
\hline CONCLUSIONS & 39 \\
\hline NOMENCIATURE & 41 \\
\hline REFERENCES & 42 \\
\hline DRAWINGS & 42 \\
\hline
\end{tabular}


Interim Radioactive Gaseous Effluent Sampling and Monitoring Criteria for Atlantic Richfield Hanford Company Facilities

APPENDIX B

ARHCO Emergency Procedure: 2.7 .7 WESF Loss of Electrical Power

APPENDIX C

ARHCO Emergency Procedure: 2.7.9 WESF Loss of Ventilation

APPENDIX D

ARHCO Emergency Procedure: 2.7.12 WESF Radioactive Gaseous Discharge 


\section{A STUDY OF THE COMPLIANCE OF THE GASEOUS EFFLUENT SAMPLING AND MONITORING SYS'IEM WITH INTERIM CRITERIA -- \\ 296-B-10 STACK, WASTE ENCAPSULATION AND STORAGE FACILITY}

\section{INTRODUCTION}

A study is underway by Battelle-Northwest to evaluate existing gaseous effluent sampling systems in ARHCO process buildings, including the 225-B Waste Encapsulation and Storage Facility (WESF). An interim report concerning the WESF effluent sampling systems [1] was issued in March of 1975.

Sampling systems for particles present in the plant's main exhaust stack, 296-B-10, and in the stages of the $K-1$ and $K-3$ HEPA filter banks were described in that report. Theoretical models with which to estimate the efficiency of the particulate sample collection devices were developed and presented in the appendix of the interim report. Using those models and accepted design practices [2] the efficiency and design of the existing sample collection devices were evaluated. Finally, various improvements to the devices were suggested. It was, however, emphasized in the interm report that a performance evaluation and firm recommendations could not be made until definite design criteria stating the purpose and performance demands of the particulate collection devices were formulated.

Since the writing of that interim report ARHCO has issued a document entitled "Interim Radioactive Gaseous Effluent Sampling and Monitoring Criteria for ARHCO Facilities", a copy of which is included in Appendix A. The document lists many performance criteria for both the sample collection devices and the instrumentation for continuously monitoring the radioactivity of the collected particulates and gases. These criteria allow an evaluation of the ability of sample collection and monitoring equipment to perform the required tasks. 


\section{OBJECTIVE}

The objective of this report is to evaluate the compliance of the WESF exhaust stack air sampler and monitor with the interim criteria established by ARHCO, and to recommend corrective actions. This evaluation is based on the previous analysis of the sample collection device contained in BNWL-B-408 and recently gathered information on the sample monitoring instrumentation and sample collection device.

Since this is the first time the interim criteria will be used in an evaluation, the first section of the report will address interpreting the criteria for the case of the facility in question. This will be followed by brief descriptions of the sampling and monitoring equipment and then an evaluation of their compliance with the criteria. A recommended plan for corrective action will then be presented.

The methods used in radiochemical laboratory analysis of the collected particulate samples have a major bearing on the accuracy of final reported concentrations of released radioactive effluents. This subject will not be addressed in this report. A study group has been formed to consider current laboratory procedures. The findings of that study are expected to be issued in a future document. Since the analytical procedures for the air samples from all of ARHCO's facilities are similar, the review will probably cover several facilities.

\section{SUMMARY}

The gaseous effluent sampling and monitoring systems for the principal gaseous effluent of the Waste Encapsulation and Storage Facility, the 296-B-10 stack, were evaluated for compliance with ARHCO's interim criteria for such systems (see Appendix A). Prior to the evaluation it was found necessary to carefully interpret the criteria. The sanpling criteria particularly required rather detailed interpretation since they were written with the assumption that the reader would have an understanding of air sampling 
design practices and air sample analytical techniques. The monitoring criteria were generally stated such that the desired interpretation was clear. There were found, however, two criteria to be in conflict with each other.

The sampling system was found to have certain stu angths and weaknesses. Generally, it was concluded that the samples being collected were not representative of the effluent airstream to the degree specified by the criteria. However, if the particulates were proved to be submicron in aerodynamic size in all circumstances, the samples are likely to be representative, if not up to the requirements. The main contributors to non-representative sampling were the delivery lines (65.70 feet long). ten bends, sublsokinetic sampling and the collector/detector. A particularly strong point of the sampling system was the choice of the location to extract the sample.

The monitoring system was found to be adequate in terms of range, most facets of operation and trend indicarion. However, the counting efficiency of the detection element was not determined or routinely checked for the beta emitting radionuclides which are of prime interest in the effluent. There were also no "fail safe" alarms to warn of malfunction of the instruments or collector vacuum. Other strengths and weaknesses of both the sampling and monitoring systems are detailed in the report.

Several recommendations for improvements in the elements of the sampling and monitoring program which are not in compliance with the criteria are outlined in the report. The deficiencies of the sampling system require extensive redesign to satisfy the criteria. Nine specific improvements were outlined for the sampling system. The weaknesses of the monitoring system should be relatively easily remedied and three suggestions for corrective action were listed.

\section{INTERPRETATION OF CRITERIA}

The criteria for sampling and monitoring gaseous effluent streams are intended as guidelines to aid in designing or upgrading 
sampling systems and procedures. They are also useful as performance standards against which gaseous effluent monitoring and sampling equipment can be evaluated. The criteria are divided into two sections -- "Sampling Criteria", and "Monitoring Criteria". Both sections are intended for both particulate and gassous radionuclides; however, since only particulates have been a concern in the sampling program at the WESF, only those portions relating to particulate radionuclides will be discussed here.

Although the interim criteria cover many important facets of obtaining radioactive particulate samples and their monitoring, there are some points of good air sampling practice assumed to be understood. Since it is important to have a common understanding and a rational interpretation of what the criteria mean, the statements relative to sampling and monitoring will be discussed in the following two sections.

\section{SAMPLING CRITERIA}

The sampling criteria cover the extraction, transport and collection of a sample of the suspended particulates from an effluent airstream. The extraction process involves the selection of the location in the airstream from which the sample is taken, the choice of the size of the sample aliquot and the separation of the sample airstream from the effluent. After being separated from the effluent, the sample airstream pius suspended particulates are transported to the collection medium. At the collection medium the sampled particulates are separated from the sample airstream and held for monitoring or analysis.

In the sampling criteria the term "representative" is used frequently. Before proceeding to discuss each criterion it is important to understand what "representative" means. A sample airstream which is representative" is one in which the concentration of suspended particulates is equal to the concentration in the total effluent. Also, the size distribution of particulates in the sample airstream is the same as that of the bulk effluent. The collected particulate sample is "representative" when its mass divided by the amount of sample air it was collected from equals the average concentration in the effluent. Many of the criteria set limits as to how far the samble airstrean $\Rightarrow \rightarrow$ 
the collected sample can deviate from representativeness. Others set requirements as to the operation of the sampling system. They will be discussed in the same order as they are presented in the interim criteria.

Criterion 1 -- Gaseous effluent sampling systems snall "extract in a 24-hour period a representative fraction of the effluent stream such that an activity release at least as low as the concentration guides given in ERDA Appendix 0524, Annex A, Table II can be measured with appropriate accuracy upon subsequent laboratory analysis". This criterion has the following footnote:

If one half of the Class I Action Level in ARH-222, ARHCO

Emergency Procedure 1.9 (or the Emergency Procedure that governs gaseous discharges for the specific facility) is less than the Table II concentration guides, use one half of the Class I Action Level from the appropriate Emergency Procedure as the basis for this criterion.

This criterion is a type of controlling criterion which covers all the components of a sampling system and procedure except monitoring. Although extraction is the only phase of sampling mechanics mentioned, the criterion implies that the radioactive particulates are transported and collected so they can be analyzed. Briefly, the criterion states that in a 24-hour period, during which the effluent activity concentration is equal to or exceeds stated levels, the amount of radioactive material collected in a representative fashion must be sufficient to permit radiochemical measurement with appropriate accuracy. The main issue in this criterion is the size of the aliquot of the effluent stream which must be withdrawn in order that the amount of radioactive particulates collected permits accurate analysis. The criterion requires that whatever the aliquot size is, the material collected will be "representative" of the bulk stream. The size of the aliquot (and thus the amount of the radioactive material collected) varies with the sample flow rate and is determined by the release level of interest and whatever constitutes "appropriate accuracy" for the analytical technique. (Errors due to deposition, low collection efficiency, etc., are assumed to be negligible in interpreting this criterion.) 
In order to determine the release level of interest the limits stated in the Emergency Procedures for the WESF (Appendix D) and the Table II values of ERDA Manual Chapter 0524[3] must be ccinsidered. Table I summarizes these limits. A prevailing stack flow :ate of 18,800 SCFM was assumed. Comparing the last two columns of the table shows that one-half the release limits of the Emergency Procedure are lower chan the Table II limits; the ${ }^{90} \mathrm{Sr}$ limit being the most restrictive.

TABLE I

RELEASE LIMITS FOR WESF *

Emergency Procedure ARH-222-2.7.12

\begin{tabular}{|c|c|c|c|c|c|}
\hline Constituent & $\begin{array}{l}\text { Weekly } \\
\text { Limit } \\
C_{i} / \text { wk } \\
\end{array}$ & $\begin{array}{c}\text { Weekly Limit } \\
\text { Concen. } \\
\mu C_{i} / c c \\
\end{array}$ & $\begin{array}{c}\text { Class I } \\
\text { Action Level } \\
\text { Concen. } \\
\mu \mathrm{C}_{\mathrm{i}} / \mathrm{cc} \\
\end{array}$ & $\begin{array}{c}\text { One-He If } \\
\text { Class I } \\
\text { Concen } \\
\mu \mathrm{C}_{\mathrm{i}} / \mathrm{cC} \\
\end{array}$ & $\begin{array}{l}\frac{024}{\text { Table II }} \\
\text { Concen. } \\
\mu C_{j} / c c \\
\end{array}$ \\
\hline${ }^{90} \mathrm{Sr}$ & $1 \times 10^{-3}$ & $1.86 \times 10^{-10}$ & $1.86 \times 10^{-11}$ & $9.3 \times 10^{-12}$ & $3 \times 10^{-11}$ \\
\hline $137 \mathrm{Cs}$ & $1 \times 10^{-2}$ & $1.86 \times 10^{-9}$ & $1.86 \times 10^{-10}$ & $9.3 \times 10^{-11}$ & $2 \times 10^{-7}$ \\
\hline Total Beta & $2 \times 10^{-2}$ & $3.72 \times 10^{-9}$ & $3.72 \times 10^{-10}$ & $1.86 \times 10^{-10}$ & $3 \times 10^{-11}$ \\
\hline
\end{tabular}

* The calculations for the concentration limits given in the amergency Procedure are as follows:

296-B-10 Stack Flowrate $=18,800 \mathrm{~cm}$

Concentration $(\mu \mathrm{Ci} / \mathrm{cc})=\frac{\text { Weekly Limit } C_{i}}{v_{\gamma}{ }_{\mathrm{wk}}} \times \frac{\mathrm{wk}}{10,080 \mathrm{~min}} \times \frac{10^{6} \mu \mathrm{C}_{i}}{\mathrm{C}_{i}} \times \frac{\mathrm{min}}{18,800 \mathrm{ft}^{3}} \times \frac{\mathrm{ft}^{3}}{28,317 \mathrm{cC}}$

One half Class I Action Level concentration $(\mu \mathrm{Ci} / \mathrm{cc})=\frac{1}{2} \times \frac{1}{10} \times$ concentration.

Thus, the criterion requires that the limits of the Emergency Procedure be used for evaluating compliance.

"Approprtate Accuracy" must be defined before it is possible to assess compliance with this criterion. A definition of that term is not specified in the criteria; therefore, for purposes of this evaluation an accuracy of $\pm 10 \%$ at the 958 confidence limit for the analysis will be assumed as "appropriate". Since the accuracy of the counting technique varies with the background radiation, analytical equipment, net counting rate and counting time, certain assumptions will be made: 
1. The laboratory analysis is performed using the existing procedure for the Beckman Wide Beta Andyzer (counting time is one minute).

2. The analysis is for beta emitters as ${ }^{9} \mathrm{Sr}$.

3. The beta radiation background is a nominal $15 \mathrm{cpm}$

With these assumptions it can be shown* that a net counting rate of $400 \mathrm{cpm}$ must be measured to achieve appropriate accuracy.

Once the concentration level and analysis accuracy requirements are established there is a minimum fraction, or sample airstream flow rate, of the total exhaust stream that must be in the sample aliquot. Since the concentration level of ${ }^{90} \mathrm{Sr}$ is the most restrictive, the sampler flow rate will be calculated for that case. (The more sertrictive the limit, the higher the sampler flow rate must be to inect the required activity.) The following is the equation used to determine beta-emitter concentrations:

$$
\begin{aligned}
\frac{\mu C_{j}}{c c}= & \text { Net } \operatorname{cpm} \times \frac{\text { disintegrations }}{0.383 \text { counts }} \times \frac{\mu C_{j} \min }{2.22\left(10^{6}\right) \text { disintegrations }} \\
& \times \frac{h r .}{F \cdot R_{.} \mathrm{ft}^{3}} \times \frac{\mathrm{ft}{ }^{3}}{28,317 \mathrm{cc}} \times \frac{1}{0.7} \times \frac{1}{24 \mathrm{hr}} .
\end{aligned}
$$

The value 0.7 is the currently assumed value for the collection efficiency of the asbestos filter (HV-70) used as a collector at WESF**. The counting efficiency of 0.383 is the lowest efficiency for the wide beta analyzer. Both the filter and counting efficiencies are conservative values yielding a higher calculater concentration than actually measured. The sampler flow rate, F.R., is in cubic feet per hour at stack conditions. Stack conditions are assumed to be atmospheric pressure and $70^{\circ} \mathrm{F}$, or standard conditions. Thus, the sampler flow rate is in SCFH (standard cubic feet per hour).

* The following equation allows the calculation of interval limits at the 958 confidence level.

Interval Limit $= \pm 1.96 \sqrt{\frac{\text { Net cpm }+ \text { background cpm }}{\text { Sample counting time }}+\frac{\text { background cpm }}{\text { background counting time }}}$

Subst+tuting in the assumed values and a net count rate of $400 \mathrm{cpm}$ the interval limits are $\pm 41 \mathrm{cpm}$ or \pm 108 .

** The 0.7 correction could also account for reduced counting efficiency due to absorption of beta particles due to embedment of the radioactive material collected on the filter media. 
Collecting constants and solving for the sample flow rate the above equation becomes :

$$
\text { F.R. }=\frac{\text { Net cpm }}{\text { Concentration limit }} \times 2.47\left(10^{-12}\right)
$$

Substituting the necessary $400 \mathrm{cpm}$ and the ${ }^{90} \mathrm{Sr}$ concentration level required, the sampler flow rate minimum is $106 \mathrm{SCFH}$. Of course, the strictness of the flow rate requirements depends on how strictly one is to observe the limits imposed by the Emergency Procedure. A strict interpretation of the concentration criteria and the assumed definition of "appropriate accuracy" requires a minimum flow rate of 106 SCFH (1.77 SCFM) through each sample collection system.

\section{Criterion 2 -- Gaseous effluent sampling systems shall "be} designed, fabricated, and operated so that the particles extracted and transported to the collector will be representative to the degree that particles 10 micrometers and smaller in the sample collected will be at least 908 of the 10 micrometer and smaller particles in the same volume of a truly representative sample. At least 908 of the radioactive gases withdrawn shall be collected on the media selected or delivered to the activity sensing chamber in flow-through monitors."

This criterion sets a performance standard for all three areas of sampling -- extraction (excluding, however, the location of the sampling point), transport and collection. The standard states that 908 of particles, within an incremental size range about 10 micrometers, aerodynamic equivalent diameter,* in the sample aliquot at

* As pointed out in the interim report, the aerodynamic equivalent diameter (AED) is defined as the diameter of a hypothetical particle of unit density (water) which would have the same settling veloctty as the actual particle.

The AED is related to the way a particle behaves aerodynamically. For spherical particles the AED $=d_{d} \sqrt{\rho^{\prime}}$ where $d$ is the particle diameter and $\rho^{\prime}$ is the particle specific gravity. The criteria require certain performance for a particle of $10 \mu \mathrm{m} \mathrm{AED} \mathrm{and} \mathrm{partlcles} \mathrm{sizes} \mathrm{determined}$ experimentally using cascade impactors are expressed in AED. Therefore, $A E D$ will be used in this report. 
the point of extraction, shall be collected. What this means can best be explained by an example. Suppose that the concentration of $10 \mu \mathrm{m}$ AED particles in the column of gas (of same diameier as the nozzle orifice) approaching the proble nozzle is 1 microtram per standard cubic foot (SCF). Further suppose that the column of gas approaches at the rate of 5 SCFM and is sampled at the rate of 4 SCFM. That would mean that in a truly representative sample $4 \mathrm{micrograms} / \mathrm{min}$ of $10 \mathrm{\mu m}$ particles would be included in the sample. Although the sample concentration may receive a positive bias due to subisokinetic extraction and a negatj bias due to deposition, the criterion states that 908 of the 4 micrograms/minute or $3.6 \mathrm{micrograms/minute} \mathrm{must} \mathrm{be} \mathrm{collected.} \mathrm{In} \mathrm{:}$ other words, the material collected divided by the volume of the sampled air may be no less than 908 of the original concentration in the gas column approaching the nozzle.

The criterion does not imply that particles larger or smaller than $10 \mu \mathrm{m}$ will not be sampled at all; in fact, more than 908 of particles smaller than $10 \mathrm{\mu m}$ and many larger particles will be collected. However, it is implied that a specific accuracy for only respirable particulates, those under $10 \mu \mathrm{m}$, is required. This performance requirement applies to both the inventory and monitored samples to be discussed later.

Criterion 3 -- Gaseous effluent sampling systems shall "operate in a continuous wode, except for short periods when the sample collection media is being changed, whenever the facility is exhausting to the atmosphere."

This criterion requires that the entire sample collection system must be operating continuously as long as the WESF $K-3$ and $K-1$ ventilation systems are exhausting to the atmosphere through the 296-B-10 stack. The only interruption can be when the sample collection medium (a filter) is being changed. Under certain emergency conditions the $R-3$ ventilation system can exhaust to the atmosphere through a steamjet -- by-passing the fans and stack -- without particulate sampling being required. 
criterion 4 - Gaseous effluent sampling systems shall "extract samples of particles and gases that are a representative aliquot of the sctinl effluerit stream."

This eriterion states that the sample airstream that is extracted from the effluent stream must be representative. The sample must be separated representatively from the effluent at a point where the particulate concentration equals the average for the airstream. Guidelines have been laid down for selecting suitable sampling locations. [2]

In general the particulates should be well mixed with the airstream throughout the plane, perpendicular to the direction of flow, where the extraction device i.3 located. If the particulates are not well mixed in the airstream, then efforts must be made to ind a point where the concentration equals the aveiage concentration.

Finally, the extraction device (commonly a nozzle with a circular opening) must separate the particulate and gaseous sample from the column of approaching air of the same diameter as the nozzle orifice. This should ideally be done such that the concentration of particulates just inside the nozzle orifice equals the concentration of the approaching air column. The degree of success in accomplishing this is a function of the degree of isokinesis*, nozzle shape, particulate size, and other factors. However, at times it may be desirable to somewhat bias the concentration to cancel a deficiency in the transport or collection phases. The desired accuracy or degree of success in accomplishing extraction is included in the requirements of the second criterion.

Criterion 5 - Gaseous effluent sampling systems shall "collect at least two samples, one of which will be designated and used exclusively as an inventory sample."

This criterion states that at least two samples of particulatos will be collected. The inventory sample is intended to be the most

"That is, the relationship of effluent air velocity to sample air velocity inside the nozzle orifice. 
accurate sample and to be used for the analysis and reporting of an official release value for radioactive particulates. It is assumed that another sample is to be used as a monitored sample. The monitored sample is that which is continually observed in-situ for the buildup of radioactive particulates. The inventory sample is not to be monitored, since the geometry of radiation detectors can adversely affect the performance of the sampling device. The intention is to use the inventory sample as the "best" and official sample. It is likely that the monitored sample would occasionally be used as a back-up or check on the inventory sample.

Criterion 6 - Gaseous effluent sampling systems "shall provide particulate and gaseous samples that have not been adversely affected by condensation of moisture."

Moisture condensation in air sampling devices is often encountered, particularly when ambient temperatures are below the dewpoint of the plant ventilation air. Condensation in extraction nozzles and transport lines can cause deposition of particulates or washout of deposited particulates. Condensation at the collection medium can dissolve certain particulates and wash the activity through the filter and also inhibit the flow of gas through the filter. These problems can contribute to serious errors in collected samples. This criterion states that condensation shall not occur in sampling devices upstream of the vacuum side of the collection medium.

Criterion 7 - Gaseous effluent sampling systems shall "be equipped with a vacuum system for sample extraction that has the same number of back-up power systems as the exhaust fans of the facility. The vacuum system shall be provided with an alarm that is activated upon the loss of vacuum."

The requirements of this criterion require no further explanation.

Criteria 8 end 9 - Gaseous effluent sampling systems shall: "provide an inventory sample which is an accurate aliquot, within a factor of two, of the absolute radioactive materials of the effluent stream. (Note: This statement relates only to the sample extraction 
and delivery capability, not to the accuracy of detection and measurement.)". ". provide inventory samples with less than 258 variation from the mean of several similar samplings at the 958 confidence level."

Criterion elght states that the collected sample can vary as much as $+1008,-508$ from an ideal sample representing the average concentration of the bulk airstream over 24-hours. This variance from representativeness includes permissible errors under Criterion ij. 2 plus errors due to location of sample extraction and measuement. of airstream flowrate and sample flowrate. (These variances ci.: called the alj.quot fraction error.) Although there is an allow... error, the error should be consistent for it should technicaliy iscome a bias) within the limitations of criterion 9.

Criterion 9 states thal in a series of repeatel sample... the airstream with constant activity enncentration the result.: mus: agree within \pm 258 nin $\gamma-f$.ve percant of the time. (That is $: 21$ repeated tests were maa: aneteer of them must agrte within $\pm 25 \%$ ).

Both of these criteria state they apply oniy to the inyento:y sample. However, since the is only n single sampie collecteci at ritsF which serves as both the inertory and minitored sample, it will be assumed that these criteria apply to it rather than to evaluati the sampling system first as an inventong sample with specific pecturrarce requirements and then as monitored sample with less clear requirements. It would be desirable to have a specified overall performance standard for monitored samples since the monitored sample is a better trend indicator when the sampling performance is improved.

Criterion 10 -- Gaseous effluent sampling systems shall "have at least an annual check to ensure that variation in effluent characteristics (particle size, mass activity concentration, etc.) have not changed significantly.

An annual check of effluent characteristics should include obtaining data on particle size, mass activity concentration, flowrate, 
dewpoint or other variables. Such data would be used in several ways: to alter operating conditions of sampling devices, to vary analytical methods and calculations, to evaluate the limits imposed by criteria an.: to check the effectiveness of airborne particulate removal systems.

\section{SAMPLING CRITERIA SUMMARY}

After this discussion on interpreting the sampling criteria it would be helpful to briefly summarize the criteria as they will be applied to this study.

1. The size of the sample aliquot shall be adjusted such that for a ${ }^{90} \mathrm{Sr}$ daily average concentration of $7.6 \times 10^{-12} \mu \mathrm{C}_{i} / \mathrm{cc}$ ( $1 / 2$ Class I Action Level) sufficient activity will be collected to permit an analysis with an accuracy of \pm 108 (at the 958 confidence level) using the present routine laboratory techniques.

2. Of the particles in the sampled aliquot, at least 908 of the ten micron, AED, particles shall be collected on the collection medium.

3. The sample collection system shall operate continuously as lonq as WESF air is being exhausted through the 296-B-10 stack, except for brief periods for changing the collection media.

4. The sampling system must perform the function of extraction such that: (1) the activity concentration at the extraction location is typical of the average activity of the bulk airstream, and (2) the sampled aliquot is separated from the portion of the airstream approaching the extraction device such that the particle concentration in the sampled aliquot is either the same before and after separation or purposely biased to offset transport and collection deficiencies in the remainder of the system.

5. At leart two samples of particulate activity will be collected -- one for an inventory function and the others for monitoring functions.

6. Moisture condensation shall not occur in the sampling devices upstream of the vacuum side of the collection medium. 
7. The vacuum system serving the sampling devices shall have a "loss of vacuum" alarm and the system shall have the same level of redundance as the fans exhausting air to the 296-B-10 stack.

8. The collected samples of particulate activity shall be a known representative fraction within + 100\%, $-50 \%$, of the average particulate activity in the bulk airstream.

9. For repeated samplings from a constant particulate activity concentration in the 296-B-10 stack 958 of the samples must agree within \pm 258 .

10. Sampling parameters such as particle size, exhaust and sampler flowrate, and exhaust air dewpoint shall be checked at least annually.

\section{MONITORING CRITERIA}

The monitoring criteria cover the use of radiation detection instrumentation to observe (monitor) in-situ the activity collected in the monitored samples discussed earlier. Many of the monitoring criteria as written need no interpretation as to their meaning. The reader is referred to Appendix $A$, to become familiar with those criteria (Nos. 3, 4, 5, 6, 7, 9, and 11). However, some comment should be made as to the interpretation of criteria Nos. 1, 2 and 8 . These will be discussed in the following paragraphs.

Criterion 1 -- Gaseous effluent monitoring systems shall, "monitor the samples collected (except for the designated inventory sample) as detailed in items 1-10 under Sampling criteria. The monitoring system shall be able to detect an activity release at least as low as one-half that required for the class I Action Level listed in ARH-222, ARHCO Emergency Procedure 1.9 (or the Emergency Procedure that governs gaseous discharges for the specific facility)."

In the case of the 296-B-10 stack sample monitor this means that a release level at least as low as one-half that required for a Class I Action Level (see Table I), shall be detectable. Whether or not such a concentration level can be deduced from a monitor detector response depends principally on the size of the sample 
aliquot, the detector efficiency and somewint on the collection medium. The currently used sample aliquot and detection devices will be the subject of evaluation of compliance with this criterion.

Criterion 2 -- Gaseous effluent monjtoring systems ihall "detect the radiation from radionuclides in the effluent stream with appropriate sensitivity for the radiation emitted."

This criterion must be interpreted as to what is meant by "appropriate sensitivity for the radiation emitted." For the purposes of this study it will be assumed that the detection instruments should be designed for the specific types of radiation (alpha, beta or gamma) expected, and have a great enough counting efficiency' when used with the selected collection media, so that only a reasonably sized aliquot of the exhaust stream particulate activity is required to accumulate sufficient activity for monitoring. In the case of the WESF where the particulate activity is predominantly $137 \mathrm{Cs}$ and ${ }^{90} \mathrm{Sr}$, a beta radiation detector must be employed and a gamma detector would also be desirable to distinguish ${ }^{137} \mathrm{Cs}$ alone.

Criterion 8 -- Gaseous effluent monitoring systems shall "be able to detect a Class II Action Level as specified in ARH-222, ARHCO Emergency Procedure 1.9 (or the Emergency Procedure that governs gaseous discharges for the specific facility) in less than 24 hours."

This criterion seems to be less restrictive than Criterion 1 , hence we interpret Criterion 8 to be met by compliance with Monitoring Criterion 1 .

Criterion 10 -- Gaseous effluent monitoring systems shall "be equipped with sufficient range to detect activity levels up to 100 times the Class II Action Level in ARH-222, ARHCO Emergency Procedure 1.9 (or the Emergency Procedure that governs gaseous discharges for the specific facility)."

This criterion sets a minimum uppex boundary for the detection range of the instrument. For the WESF 296-B-10 stack the minimum upper bound would be a total beta concentration of $3.72 \times 10^{-8}$ 
$\mu \mathrm{Ci} / \mathrm{cc}$ for two successive 24-hour periods (for gamma the bound would be $\left.1.86 \times 10^{-8} \mu \mathrm{Ci} / \mathrm{Cc}\right)$, according to $\mathrm{ARH}-222-2.7 .12$ and assuming a stack flowrate of 18,800 SCFM. As with criterion. No. 1 , the ability of a detector to cover that range depenc: or the sizo of the sample aliquot, detector efficiency, and dynami $=$ range of the detector. 
DESCRIPTION OF EXISTING GASEOUS EFFLUENT SAMPLING AND MONITORING SYSTEMS AT THE 296-B-10 STACK

The sampling system at the 296-B-10 stack obtains and monitors particulate samples from the combined $\mathrm{K}-1$ and $\mathrm{K}-3$ exhaust airstream from the WESF. Some details concerning these exhaust airstreams will be given and then the 296-B-10 stack sampling and monitoring systems will be described.

\section{K-I AND K-3 VENTILATION SYSTEMS}

The areas of the WESF having a potential for contamination are ventilated by the $k-1$ and $k-3$ exhaust systems. The $k-1$ exhaust system, diagrammed in Figure 1, provides ventilation to the change room, operating gallery, service gallery and other normally clean but potentially contaminated areas. The $\mathrm{K}-3$ exhaust system, diagrammed in Figure 2, ventilates the process cells, the canyon area above the cells and the discharge from the air sampler vacuum syster. Both exhaust airstreams pass through two stages of HEPA filtration and then combine in the 296-B-10 stack. The prevailing flowrate of the combined airstreams is $18,800 \mathrm{SCFM}$ in the 42 -inch ID stack. Each exhaust system is provided with two fans, one on-line and the other on standby. The fans are supplied with electricity from the main power circuit for the WESF and a diesel generator provides an automatic back-up power source in the event of a power failure (see the Emergency Procedures included in Appendices $B$ and $C$ ). The K-3 exhaust system is provided with an automatic steam jet exhauster as a final emergency back-up. [7] The steam jet exhausts through a separate stack which is not sampled or monitored for radioactive particulates.

\section{SAMPLE COLLECTION SYSTEM}

Since the time the interim report was issued the 296-B-10 stack air sampling system has been modified and new descriptive information about the stack and probe has been made available. Figure 3 is a diagram of the existing system. The hot air addition device has been eliminated and the probe is located much higher in the stack than indicated on the air sampler blueprint. [11]

Figures 4 and 5 are photographs showing the orientation of most of the system components. 


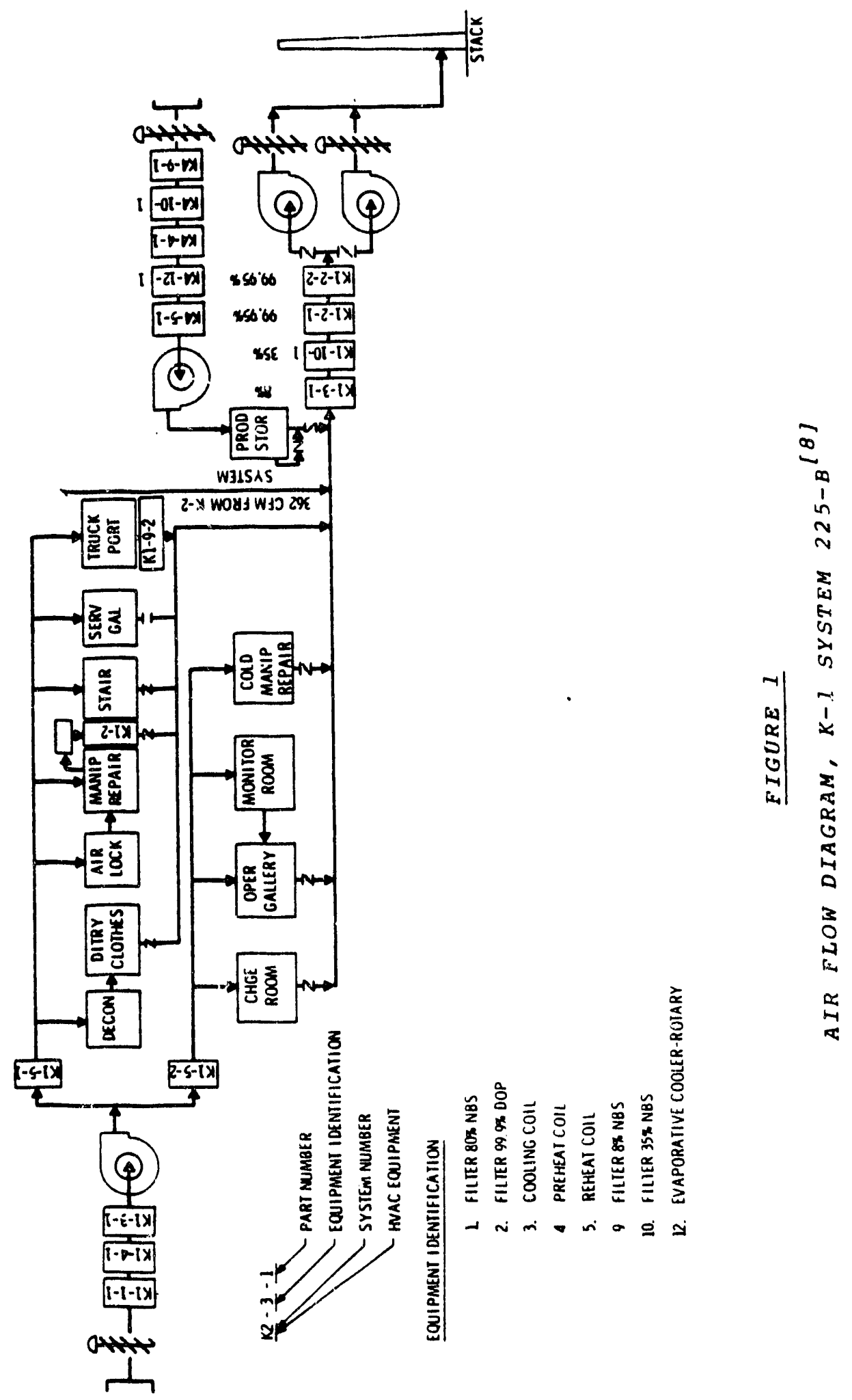




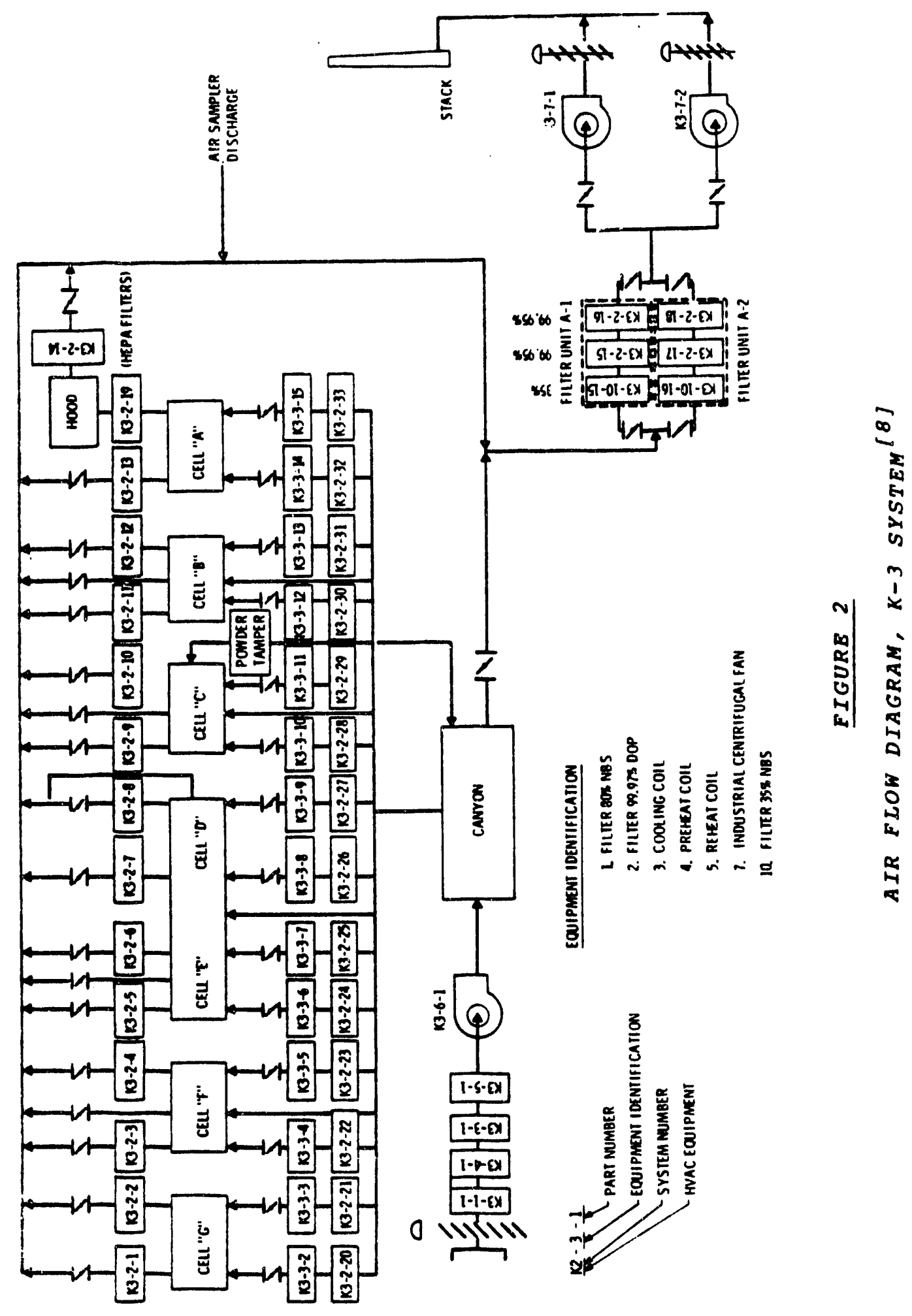




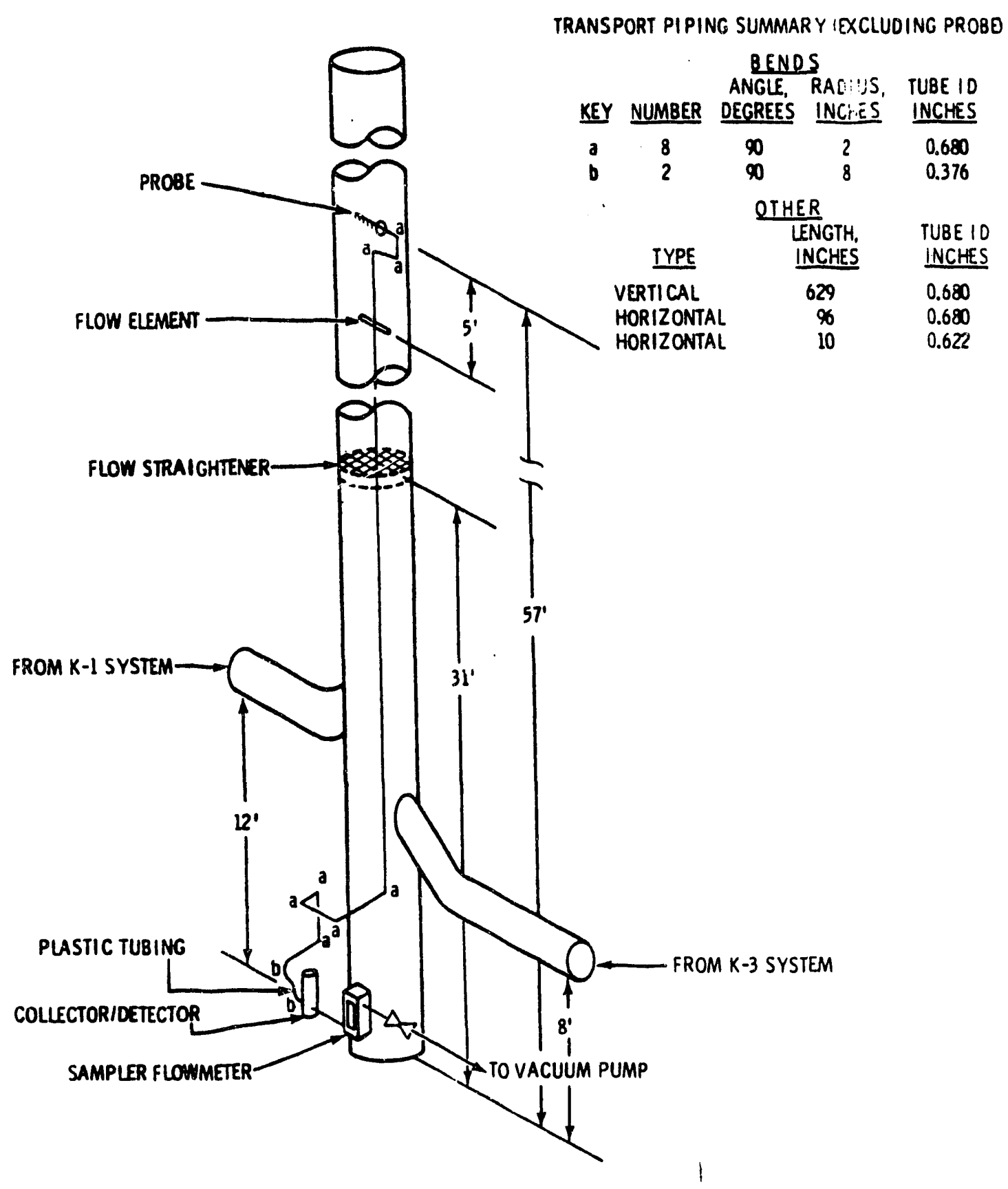

FIGURE 3

296-B-10 STACK SAMPLER [1],13] 


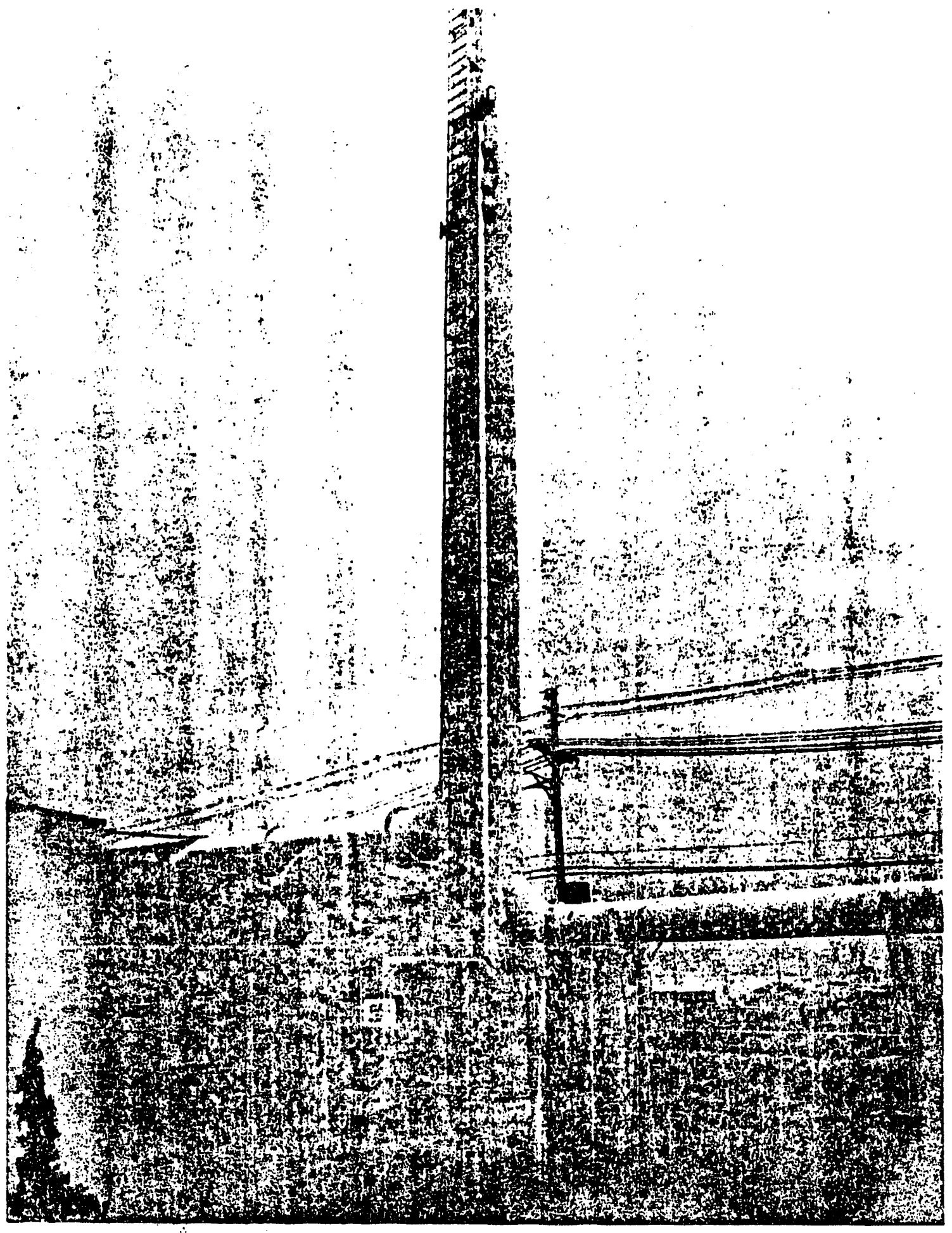

FIGURE 4

296-B-10 STACK AND SAMPLER

Neg. NO. PNL 750048-10 


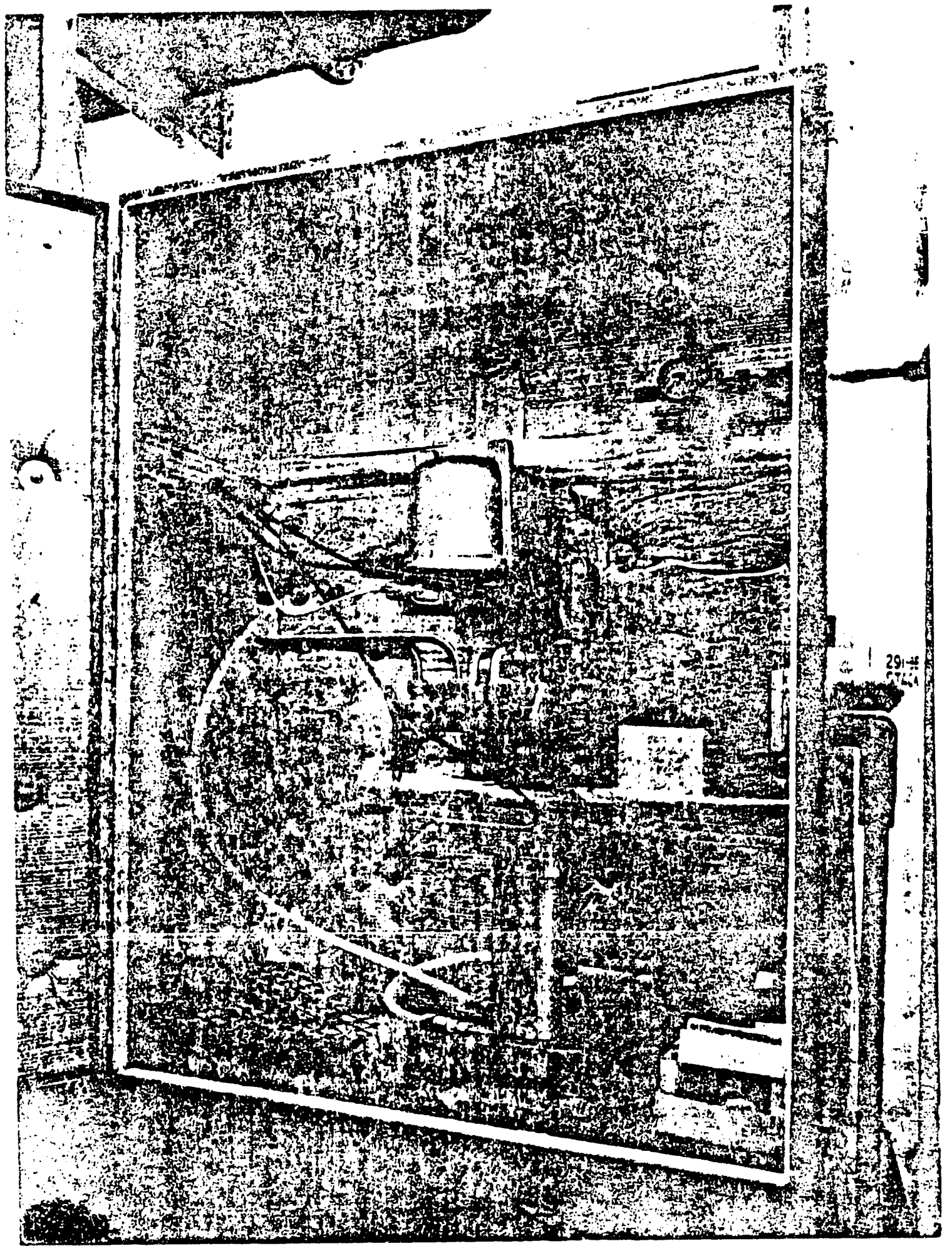

FIGURE 5

296-B-10 STACK FILTER-DETECTOR

Neg. No. 750048-13 
The extraction device is a multinozzle probe (Figure 6), located on a stack diameter at the 57-foot level of the 42-inch ID stack. [13] The five nozzles have orifice sizes ranging from 0.41 to 0.62 inches ID and are attached to a 1 -inch schedule 40 pipe which serves as a manifold. The sample airstream is tien transported through lengths of stainless steel and plastic tubing (see Figure 3) to the collector. The transport piping is insulated and electrically heated to maintain a temperature of at least $38^{\circ} \mathrm{F}$. The particulate collector is a $47-\mathrm{mm}$ asbestos fiber filter (Hollingsworth \& Vose, HV-70) which has a collection efficiency of at least 968 for a $0.3 \mu \mathrm{m}$ DOP aerosol. [2] The filter is mount is ${ }^{2]}$ ide a Hanford design collector/detector, [6] and is changed at le ${ }^{[6}$ daily -- except during weekends when it is not changed unless a larger than normal release is monitored.

Following the collector/detector is a variable area flowmeter (Dwyer Model PMB-55) which is checked and set daily so that it reads 90 SCFH by adjusting the valve just downstream of the flowmeter. Correcting the sample flowrate for variations in vacuum pressure and seasonal temperature changes it becomes about 80 SCFH \pm 68 . The vacuum supply is a pair of 18-horsepower vacuum pumps (Hoffman Centrifugal Exhausters, Model 4109A) -- one on-line and the other on standby. [12] The vacuum pumps, which also serve the other air samplers in the WESF, are connected both to te main power circuit and the automatic diesel back-up power generator mentioned earlier (Appendices $B$, and $c$ ). In the event a vacuum pump fails both audible and visual alarms are activated in the operating gallery.

\section{MONITORING SYSTEM}

A block diagram of monitoring instrumentation associated with the 296-B-10 stack sampler is shown in Figure 7. $[4,10]$ The detector is a mica window GM tube, Eon-type 6210H, with a mylar film to protect the window. The efficiency of the assembled collector/detector was estimated once using a 4,904 dpm disc gamma radiation source and was found to be 5\%. The signal is sent from the detector-decouplor arrangement to an amrifier, signal discriminator and count-rate meter as shown in the block diagram, Figure 7 . 




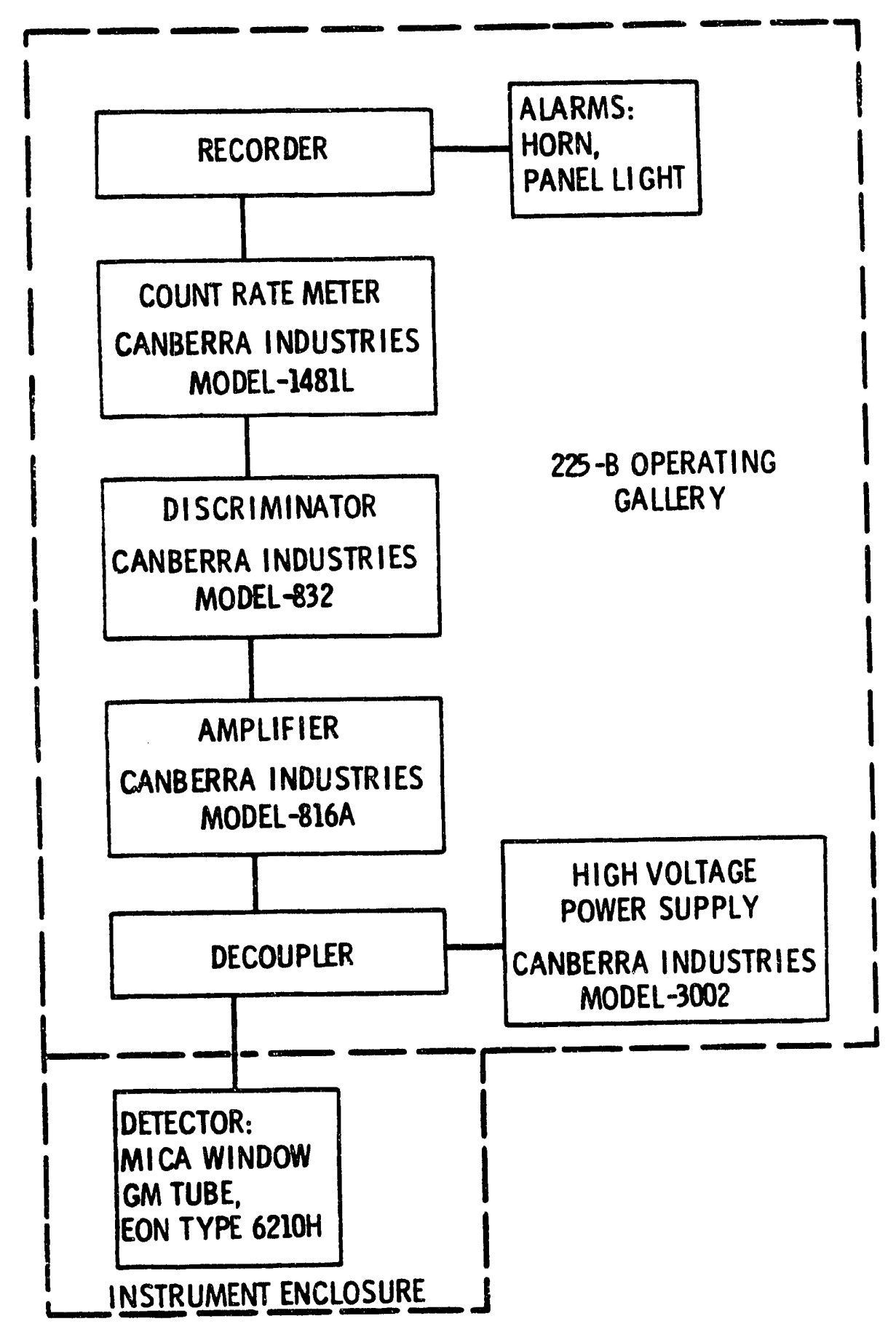

FIGURE 7

296-B-10 STACK SAMPLE MONTTOR INSTRUMENTATION BLOCK DIAGRAM $[9,10]$ 
The count rate meter has both logarithmic and 1 inear scales. The linear scale has full scale ranges from 10 to 500,000 counts per second while the fuil scale ranges in the logarithmic mode are 10 to 100,000 counts per second. For normal operation the 10 count per second linear scale is used. The output of the count rate meter is also read on a moving strip chart recorder. The recorder has a 0-10 millivolt range. A 1008 reading on the recorder is equivalent to the full scale reading of whichever range the count-rate meter is set on. There are audible and visual alarms activated in the WESF operating gallery when the recorder reaches 808 of full scale ( 8 counts per second, currently).

The monitoring instrumentation is checked bi-weekly with a radiation source to check if it responds. The accuracy of the count rate meter readings in response to a signal generator is checked on a quarterly basis. The counting efficiency of the collector/detector is not checked and has never been accurately measured.

The monitoring instrumentation is supplied by an "uninterruptible" power system, i.e.; after loss of normal power, the diesel generator is automatically started (Appendix B). In the event the generator fails, the instruments can operate on batteries for up to thirty minutes. The switching between power sources is automatic. visual and audible alarms in an occupied area are activated in the operating gallery when this occurs. 
EVALUATION OF THE COMPLIANCE OF THE SAMPLE COLLECTION SYSTEM WITH THE INTERIM CRITERIA

This evaluation of the compliance of the existing gaseous effluent sample collection system with the interim criteria will be based on the system's performance for collecting samples of ten micron aerodynamic size particulates from the 296-B-10 stack when the effluent stream is flowing at the prevailing rate of 18,800 SCFM. It should be remembered that experimental measurements of the system performance have not been made. The performance for the existing system is estimated by using knowledge of accepted sampling practices and theoretical and empirical models.

The subjects of sample aliquot selection and sampling device performance will be discussed first. Following that, under the subheading "Other Criteria compliance", the problem of continuous operation, the number of samples collected and the number of back-up power systems will be discussed.

\section{SAMPLE ALIQUOT SELECTION}

Selecting the proper sample aliquot includes choosing the sampling flowrate and the location of the probes. The sample flowrate of the existing system is somewhat low to collect enough activity during a 24-hour period when the average concentration of $90 \mathrm{sr}$ would exceed one-half of the Class I Action Level as required by criterion No. 1. Presently, allowing for variations in temperature and vacuum pressure the sample flowrate averages about $80 \mathrm{sCFH}$ rather than the 106 SCFH minimum calculated earlier in this report (see page 8). However, the counting error at the 958 confidence level for the most restrictive limit, ${ }^{9} \mathrm{Sr}$, would only be \pm 128 at the present flowrate.

The location of the sample extraction probe is well chosen. The probe is five duct-diameters from the stack top and eleven ductdiameters from the highest junction of a feed duct to the stack. There is also a flow straightener 24-1/2 feet below the probe, thus, channelling of the airstream is not likely to be a problem. Also, the airflow in the stack is highly turbulent which should provide uniform mixing of particulates through a stack cross-section. The 
air velocity should also be reasonably uniform along the chosen stack diameter.

The nozzles on the probe (see Figure 6) appear to be spaced such that each nozzle draws a sample from one of five equal annular areas of the stack cross section.* Contrary to good practice the nozzles sample from each equal area at different flowrates is shown in Table II.t

TABLE II

SAMPLING FLOWRATES THROUGH NOZZLES OF STACK SAMPLING PROBE

\begin{tabular}{|c|c|c|c|c|}
\hline Nozzle & $\begin{array}{l}\text { Orifice } \\
\text { Cross-Section } \\
\text { Area, in. } 2 \\
\end{array}$ & $\begin{array}{c}\text { Fraction of } \\
\text { Total } \\
\text { Orifice Area }\end{array}$ & $\begin{array}{l}\text { Flowrate } \\
\text { SCFH }\end{array}$ & $\begin{array}{l}\text { Velocity } \\
\mathrm{ft} . / \mathrm{sec} .\end{array}$ \\
\hline $\begin{array}{l}\text { A } \\
\text { B } \\
\text { C } \\
\text { D } \\
\text { E }\end{array}$ & $\begin{array}{l}0.304 \\
0.234 \\
0.132 \\
0.234 \\
0.304 \\
\end{array}$ & $\begin{array}{l}0.252 \\
0.194 \\
0.109 \\
0.194 \\
0.252 \\
\end{array}$ & $\begin{array}{r}20.2 \\
15.5 \\
8.7 \\
15.5 \\
20.2\end{array}$ & $\begin{array}{l}2.66 \\
2.65 \\
2.64 \\
2.65 \\
2.66\end{array}$ \\
\hline TOTAL & 1.208 & $1.00=$ & $\Leftrightarrow$ & \\
\hline
\end{tabular}

In other words, some regions in the stack contribute more to the total sample aliquot than others. The rationale for this particular design has not been discovered. In the case of this stack where the airstream is well mixed, this error is probably of little consequence.

* There is ambiguity here, since the spacing of the nozzles from the stack centerline are incorrectly dimensioned in the original blueprint.

t In analyzing gas flow through this multi-nozzied probe the assumption is made that the ratio of volume flowrate through one of the nozzles to the total flow is equal to the ratio of the nozzle orifice area to the total area of all the nozzles. This is only approximately true since the flow through each nozzle will be influenced by friction and thus pressure drop in that nozzle. It is desirable that each nozzle sample from an annular cross sectional area equal to those sampled by the other nozzles. Also, each equal area should be sampled at the same flowrace and velocity if the velocity is uniform across the stack. In the case of a thoroughly mixed stream with negligible particle stratification, these considerations are of lesser consequence. Experimental verification of uniformity of flow and mixing is desirable. 


\section{SAMPIING SYSTEM PERFORMANCE}

The performance of the sampling system for collecting particles of a certain size is the product of the way the system performs the functions of extraction, transport and collection.

Extraction -- In an earlier paragraph the first problem of extraction, sample aliquot selection, was addressed. It was concluded that the sample aliquot was reasonably well chosen and was close to being within the restrictions of criteria 1 and 4 . The problem of separating that sample aliquot from the bulk airstream will be addressed here.

It has been noted earlier that the flowrate of the bulk airstream was 18,800 SCFM and the stack inside diameter was 42-inches. The average airstream velocity will therefore be about 33 feet per second. As shown in Table II, the air velocity through the sampling nozzle orifices is about 2.6 feet per second. The fact that the velocity in the orifice is about one-twelfth that of the bulk airstream results in a bias of the particle size distribution of the sample airstream relative to the bulk airstream. Also factors such as the bluntness of the nozzle edges may tend to contribute to that bias to an unknown degree.

The particle size distribution bias due to the difference between the sampling and bulk air velocities has been calculated using methods described in the appendix to the interim report. The results are shown in Table III for particles of various aerodynamic equivalent diameters* and for nozzles $A$ and $C$.

The table shows a serious bias for particles larger than $2 \mu \mathrm{m}$, AED. Thus, there will be about six times as many $10 \mu \mathrm{m}$ AED particles in the sample aliquot immediately after sample extraction from the stream than would be representative. This large bias is contrary to the requirement of Criterion 2. This bias may be compensated to a degree, as will be discussed later.

* A similar table is found in the interium report, but the bias values calculated were for the actual particle sizes indicated which were to have a specific gravity of 4. Also, the sampling air and stack velocities were slightly different. 
TABLE III

BIAS OF PARTICLE CONCENTRATION IN THE SAMPLE ALIQUOT CAUSED BY SUBISOKINETIC SAMPLING

$\begin{array}{ccc}\begin{array}{c}\text { Particle Size } \\ \mu \mathrm{m}, \text { AED }\end{array} & \text { Nozzle } & \text { Bias }=\frac{\text { Concentration in Sample Aliquot }}{\text { Concentration in Stack Airstream }} \\ & \text { A-0.622 in. ID } & 1.0 \\ 1 & & 1.1 \\ 2 & & 1.3 \\ 5 & & 2.8 \\ 8 & & 4.8 \\ 10 & & 5.9 \\ 0.5 & \text { C-0.41 in. ID } & 1.0 \\ 1 & & 1.1 \\ 2 & & 1.5 \\ 5 & & 3.6 \\ 8 & & 5.9 \\ 10 & & 7.1\end{array}$

There is an effort underway to design a new probe to extract the sample airstream ioskinetically at a flowrate of 2 SCFM. This new probe would probably cause little bias of the amount of particulates in the sample stream. Also, the sample aliquot size would be sufficient to meet Criterion 1 .

Transport -- The sample transport function of the sampling system is accomplished by the probe nozzles, probe manifold, lengths of stainless steel and plastic tubing, various fittings and the inlet chambers of the collector/detector. A summary of the principal lengths of tubing is given in Figure 3. Following the computational methods outlined in the interim report the fractional delivery of various sized particulates through the transport lines (except the collector/detector) has been estimated as shown in Table IV. 
TABLE IV

FRACTIONAI DELIVERY OF PARTICLES THROUGH SAMPLE TRANSPORT LINES

\begin{tabular}{|c|c|c|c|c|c|c|}
\hline \multirow[b]{2}{*}{$\begin{array}{c}\text { Particle } \\
\text { AED } \\
\mu \mathrm{m} \\
\end{array}$} & \multicolumn{6}{|c|}{ Computed Fractional Delivery Through: } \\
\hline & Probe & Bends & $\begin{array}{l}\text { Horizontal } \\
\text { Lines }\end{array}$ & $\begin{array}{l}\text { Vertical } \\
\text { Lines } \\
\end{array}$ & $\begin{array}{c}\text { Overall } \\
\text { Mono- } \\
\text { disperse }\end{array}$ & $\begin{array}{l}\text { Overall } \\
\text { Poly- } \\
\text { disperse }\end{array}$ \\
\hline 0.5 & 1.00 & 1.00 & 1.00 & 1.00 & 0.99 & 0.97 \\
\hline 1.0 & 1.00 & 0.98 & 1.00 & 1.00 & 0.98 & 0.91 \\
\hline 2.0 & 0.99 & 0.93 & 0.99 & 1.00 & 0.91 & 0.76 \\
\hline $\begin{array}{l}5.0 \\
8.0\end{array}$ & $\begin{array}{l}0.95 \\
0.89\end{array}$ & $\begin{array}{l}0.62 \\
0.30\end{array}$ & $\begin{array}{l}0.94 \\
0.86\end{array}$ & $\begin{array}{l}0.99 \\
0.97\end{array}$ & $\begin{array}{l}0.55 \\
0.22\end{array}$ & $\begin{array}{l}0.49 \\
0.35\end{array}$ \\
\hline 10.0 & 0.84 & 0.15 & 0.79 & 0.94 & 0.09 & 0.29 \\
\hline
\end{tabular}

The estimated overall fractional penetrations are shown under two headings -- "monodisperse" and "polydisperse". The values under the heading "monodisperse" are the computed penetrations for the aerodynamic equivalent particle sizes listed. Under the "polydisperse" heading are the computed penetrations for log-normally distributed aerosols with aerodynamic equivalent mass median diameters as listed. In light of Criterion 2 the value of interest is the fractional delivery of monodispersed particles of size $10 \mu \mathrm{m}$ AED. The delivery of particles of this size is estimated to be very poor.

A source of further loss of penetration is the collector/ detector device. The device is too complex to compute penetration values; however, experimental measurements of particle losses have been measured for the device (see page 23 of reference No. 1) and are shown in Table $v$. The table shows that the collector/detector would further reduce the overall particle delivery to the collector. 


\section{TABLE V}

PERCENT OF INLET SAMPLE PARTICLTS DEPOSITED ON COMPONENTS OF THE COLLECTOR/DETECTOR UNIT

\begin{tabular}{|c|c|c|c|c|}
\hline \multirow[b]{2}{*}{$\begin{array}{c}\text { Particle } \\
\text { ABD } \\
\text { Im }\end{array}$} & \multicolumn{3}{|c|}{ Percent Deposited } & \multirow[b]{2}{*}{$\begin{array}{l}\text { Fractional } \\
\text { Penetration }\end{array}$} \\
\hline & $\begin{array}{l}\text { st. Stl. } \\
\text { Inlet Hose } \\
\text { Connector }\end{array}$ & $\begin{array}{l}\text { Distributor } \\
\text { Ring and } \\
\text { Cavity Walls }\end{array}$ & Total & \\
\hline $\begin{array}{l}0.8 \\
2.5 \\
6.0\end{array}$ & $\begin{array}{l}0.47 \\
6.4 \\
4.7\end{array}$ & $\begin{array}{l}0.47 \\
27.0 \\
54.7\end{array}$ & $\begin{array}{l}0.94 \\
33.4 \\
59.4\end{array}$ & $\begin{array}{l}0.99 \\
0.67 \\
0.40\end{array}$ \\
\hline
\end{tabular}

Collection -- As mentioned earlier the collection medium for the particulate sample is the asbestos fiber filter HV -70 . For the estimated face velocity at the filter the collection efficiency for $0.3 \mathrm{\mu m}$ DOP particles is essentially 100\%.[2]+ $\mathrm{It}$ can be assumed that the collection efficiency will be the same for the large particles of interest.

Total system -- If it is assumed that the fractional transport through the delivery lines and probe can be multiplied by an average bias for each particle size caused by the subisokinetic sampling, then the overall fractional delivery is estimated to be that shown in Table VI.

- the face velocity at the filter is equal to the sample flowrate divided by the area of the filter. In this case the face velocity is about $114 \mathrm{~cm} / \mathrm{sec}$.

+ Quality control should be exercised locally by a testing program on purchased filter media. There have been some cases known where efficiency was non-uniform from point to point in the bulk sheet. 
TABLE VI

SAMPLING LINE DELIVERY INCLUDING SUBISOKINETIC BIAS

$\begin{array}{cc}\begin{array}{c}\text { Particle } \\ \text { AED } \\ \mu \mathrm{m}\end{array} & \begin{array}{c}\text { Fractional Extraction } \\ \text { and Delivery Bias }\end{array} \\ 0.5 & 0.99 \\ 1 & 1.08 \\ 2 & 1.27 \\ 5 & 1.76 \\ 8 & 1.21 \\ 10 & 0.59\end{array}$

Thus, the sub-isokinetic bias, being highly positive, more than offsets the sample delivery line loss except for the $10 \mathrm{\mu m}$ particles. This is a fortuitous compensation and does little to assure the accuracy of the sample delivered to the collector. (Note that if there were a new probe sampling isokinetically at the present flowrate coupled to the existing delivery lines this compensation would not occur.) Were the existing system to be operated nearly isokinetically the delivery line losses would be very large. However, the required flow for isokinetic conditions (16 SCFM) could not be drawn through the system in its present configuration due to pressure drop across the collector-filter.

When deposition in the collector/detector is also taken into account the total system fractional penetration will be like that shown in Table $v$. Thus, it can be concluded that the total performance of the sample collection device is poor for particles larger than $5 \mathrm{\mu m}$, AED. It can further be concluded that the sample collection does not conform with the performance required by Criteria 2, 4, and 8 as far as can be theoretically estimated.

Conformance of the sample collection device with criterion 9, requiring certain repeatability or precision, cannot be evaluated until experiments are conducted where reproducible amounts of a $10 \mathrm{\mu m}$ AED aerosol are dispersed into the stack airstream several times and the collected samples analyzed. There does not, however, seem to be any reason to suspect that the results from such repeated tests would not have the required precision. 
Finally, there is not presently a problem of condensation adversely affecting the performance of the sample collection system. The relative humidity of the exhaust airstream is quite low. However, if that condition were to change, which is not likely, there could develop a potential for water condensation in the sample-transport lines with the resulting problems mentionec earlier (page 11). The present heat tracing of the sample delivery line would be inadequate to retard condensation if the exhaust air relative humidity increases. However, inasmuch as condensation is not a current problem the overall system does conform with criterion 6 .

\section{OTHER Criteria COMptiance}

There is yet the sample system conformance with the Criteria Nos. 3, 5, 7, and 10 to be addressed. The topics to be considered are the number of samples collected, the operation of the system, the back-up power supply to drive the sampling system, and the question of annual sampling parameter checks.

Inventory and Monitoring Sampler Requirements -- There is currently one particulate sample collected from the 296-B-10 stack. This sample serves the function of both an inventory and monitored sample. Serving this dual purpose limits the accuracy of the sample for inventory purposes because of the arrangement and limited sampling rate required for the collector/detector. This system does not conform to Criterion 5 .

Back-Up Power -- Continuity of operation -- The sample collection system is operated continually while air is being exhausted through the 296-B-10 stack. In compliance with criterion 7 there are as many mechanical and electrical back-up vacuum systems as there are for the exhaust fan system. As required by criterion 3 , there is continually a particulate sample being collected except for the few minutes each day it takes to renew the collection medium. When there is a loss of vacuum at the plant vacuum manifold there are actuated both audible and visual alarms. However, if for some reason vacuum were lost at the stack collector/detector it would go unnoticed until the time when the collection filter 
were changed.

Annual Check of Sampling Parameters -- With respect to an annual check of sampling parameters, Criterion 10, there is no present program to perform that service. The only parameter bei.uy checked is the exhaust flowrate in the stack--and that is being monitored continualiy by the flow element with readout in the $225-B D$ building. There is, however, a current work order for particle size determinations in the $\mathrm{k}-3$ exhaust duct.

EVALUATION OF THE COMPLIANCE OF THE MONITORING SYSTEM WITH THE INTERIM CRITERIA

The evaluation of the existing monitoring system will be divided into two topics. First, the compliance with requirements for appropriate detectors, and sensitivity will be discussed. Following that will be a discussion about compliance with criteria relating to operating the monitoring system.

SENSITIVITY AND CHOICE OF DETECTORS

The radionuclides of principal interest in the effluent stream are ${ }^{137} \mathrm{Cs}$ (both a beta and gamma emitter) and ${ }^{9} \mathrm{Sr}$ (a beta emitter). It is therefore required that there be a beta radiation detector to monitor the particulate sample with enough sensitivity to detect one-half of a class I Action Level release for ${ }^{0} \mathrm{Sr}$ during a 24-hour period with a reasonable sample aliquot size.* With the present aliquot of $80 \mathrm{SCFH}, 1100$ dpm** of ${ }^{9} \mathrm{Sr}$ would be collected during a 24-hour period where the ${ }^{9}{ }^{\circ} \mathrm{Sr}$ release was $9,3 \times 10^{-12} \mu \mathrm{Ci} / \mathrm{cm}^{3}$. Even with a detector efficiency of 158 the counting rate would be 3 cps which is above the usual

- Since the subject of detector sensitivity is being addressed here, it is assumed that 100 of the particulates in sample aliquot are on the collected sample. If it were stipulated that the efficiency of the sample collection device was also to be factored into the detection sensitivity, then a much larger sample aliquot would be necessary.

** ${ }^{90} \mathrm{Sr} \mathrm{dpm}=\frac{9.3 \times 10^{-12} \mu \mathrm{Ci}}{\mathrm{cm}^{3}} \times \frac{80 \mathrm{ft}^{3}}{\mathrm{hr}} \times 24$ hours $\times \frac{2.2\left(10^{6}\right) \mathrm{dpm}}{\mu \mathrm{Ci}} \times \frac{28,317 \mathrm{~cm}^{3}}{\mathrm{ft}^{3}}$

$=1110 \mathrm{dpm}$ in 24 hours. 
background in the detector. This would be suitable to comply with. both Criteria 1 and 2 . However, a final judgement would need to be reserved until the beta counting efficiency of tine detector was experimentally measured. (Counting geometry considerations would place the efficiency of the system for ${ }^{90} \mathrm{Sr}$ beta at $15-208$. ) It is likely that the existing monitor will detect, with reasonable assurance $(2 \times$ background $)$ a trend towards the release level of concern.

With regard to the maximum range of the detector instrumeniation, the amounts of radioactivity collected and detected (assuming a 58 counting efficiency) have been calculated ios: a ralease 100 times in excess of the class II Action Level arid the present sample aliquot size. The results are shown in Table VII.

\section{TABLE VII}

MAXIMUM REQUIRED COUNTIING RANGE

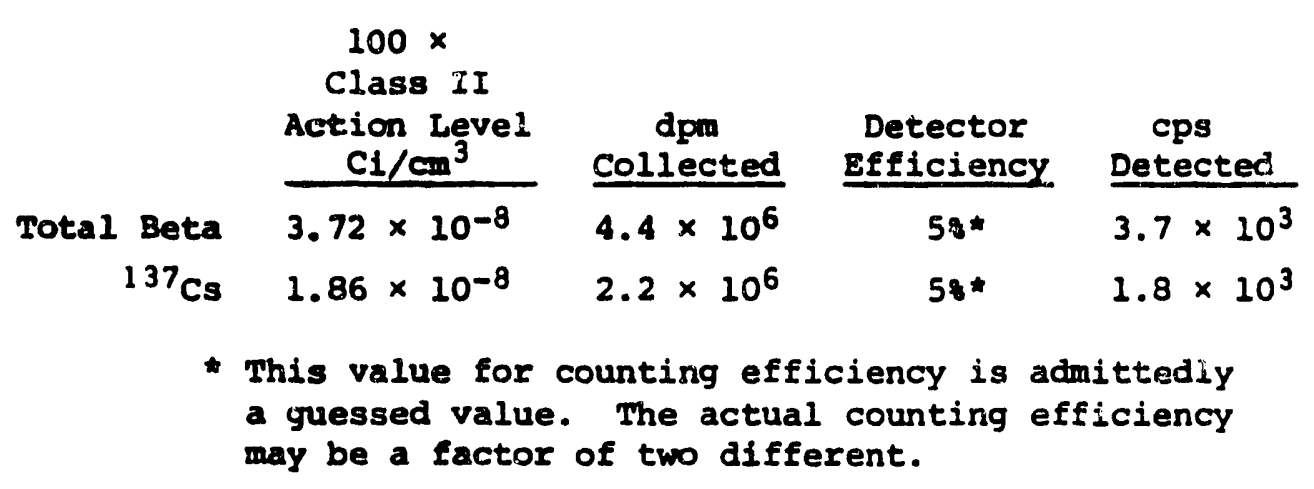

The table shows that the highest count-rate would be measured for one hundred times the class T Action Level for total beta. This count rate is within the instrument's maximum range of $5 \times 10^{5}$ cps, thereby satisfying Criterion 10 .

\section{OPERATION OF MONITORING INSTRUMENTATION}

The remaining criteria are concerned with the operation of: the monitoring instrumentation. The compliance with each of these crj.teria will be briefly discussed. 
Continuity of operation -- As required by the criteria the monitoring instrumentation operates continuously. Continuous operation is insured by two back-up electrical power systems, wh eas, the exhaust fans have a single electrical power back-up. Thu, the present system meets and exceeds the requirements of Criteria Nos. 3 and 4.

Recording and Alarms -- There are presently alarms indicating a switch to emergency power, a loss of vacuum at the vacuum pumps and at 808 of full scale on the count-rate recorder. All of these alarms are both audible and visual in a continuously occupied area of the WESF. There are presently no "fail safe" alarms indicating monitoring instrumentation malfunctions or a loss of vacuum at the collector/detector. The air sample count rate recorder triggers an alarm at 808 of scale regardless of which scale it is on. On the 0-10 CPS scale, which is normally used, the alarm therefore sounds at 8 CPS which may be higher than required; however, judgement as to whether or not the alarm is consistent with Criterion No. 7 must be reserved until the counting efficiency of the detector is determinel. The alarm should sound when a ${ }^{90} \mathrm{Sr}$ release of at least $1.86 \times 10^{-1}$ ' $\mu C i / c c$ occurs during 24-hours. This provision for recording and alarm actuation does meet criterion No. 5; however, criteria wos. 6,7 , and 9 are not fully satisfied.

Routine Instrumentation check -- The present routine for checking the monitoring instrumentation does not meet the requirement, criterion No. 1l, of being calibrated regularly. The instrumentation response to an artificial signal is calibrated quarterly but the detection efficiency is not measured.

\section{RECOMMENDATIONS}

It has been pointed out that the sample collection and monitoring systems are deficient in complying with some of the goals of the interim criteria. In the following paragraphs certain recommended corrective actions will be outlined for each system. 


\section{SAMPLE COLLECTION SYSTEM}

From the evaluation of the sample collection system it is apparent that the area most needing improvement is the collection of multiple representative samples. In the interim feport several recommendations were made, including some which could be achieved quickly. It is felt that these recommendations (excent the improved collector/detector) would achieve only a small improvement to the present system's performance. Rather than attempting to modify the present sampling system a more comprehensive approach is needed. Some of the elements of that approach should be:

1. Collect at least two samples as stipulated in the criteria, with one reserved as an inventory sample. This would allow obtaining a "best" sample of the suspended particulates in the effluent stream without the hindrance of present collector/ detector configurations.

2. Select extraction locations for all samples which have been experimentally proven to be representative of the average particulate concentration in the airstream. Possible candidate locations are the present location or in each of the two ducts exhausting to the stack.

3. Extract from the effluent stream an aliquot as large as practical considering the maximum face velocity and the reasonable size of the collection filter.

4. The inventory sample should be extracted with minimum qualification. Ideally, the collector should be placed directly behind an isokinetic nozzle and this assembly held in the stack stream. At the least a very short delivery line should be provided which can be easily removed and particle contamination on the tube walls accounted for occasionally. The sample should be extracted isokinetically to eliminate reservations of using a biased sample.

5. The sample extraction and transport piping for the monitored sample needs to be shorter and simpler than the existing piping. The unnecessary bends, horizontal piping, rough pipe joints and plastic tubing must be avoided. The monitored sample may be 
either extracted separately from the inventory sample or extracted as a subsample from the inventory sample airstream. The extraction must occur with a miaimum of bias to the sample.

6. Improve the delivery efficiency of particles throusin the collector/detector to the collection medium. This would be the most important single improvement for the monitored sample.

7. When such techniques become available, experimentally test the performance of the sample collector devices. It may even be desirable to pretest improved devices before final installation.

8. Institute a schedule to annually check the sampling parameters and performance.

The implementation of these recommendations should result in a sample collection system that meets the expected performance standards.

\section{RADIOACTIVITY DETECTION SYSTEMS}

There were a few areas where the existing radioactivity monitoring system did not satisfy the criteria. The recommendations to correct these deficiencies are:

1. The counting efficiency for beta radiation should be measured. This would verify whether or not the detector can detect above background the release level required. The counting efficiency should be determined for several standard sample discs of different amounts of beta activity. The samples should simulate the filter media. Compliance with Monitoring Criteria Nos. 1,2 , 7 and 10 could then be better evaluated.

2. Develop "fail safe" alarms to indicate detector instrumentation malfunction and loss of vacuum at the collector/detector.

3. Implement a program and develop the technique to quarterly check the counting efficiency calibration. 


\section{CONCLUSIONS}

During the development of this evaluation it was found that the Sampling and Monitoring Criteria needed careful interpretation. Therefore, a major section was devoted to explain to the reader how the criteria are interpreted for this evaluation.

In evaluating the sampling system it was found that the samples collected do not meet the reasonable requirements for representativeness set down in the criteria. The monitoring instrumentation was found to be undifferentiating for the two principal radionuclides present in the effluent, but was rather designed as a general beta radioactivity trend indicator. The instrument has not been calibrated as a beta detector. Other deficiencies for each system were pointed out. Several specific improvements were recommended to bring the system into compliance with the criteria. Finally, it has been observed for this and other effluent samplers and monitors that detailed descriptive information on each system is very difficult to obtain. It cannot be emphasized enough the need for well orqanized and reliable information on each system. 
NOMENCLATURE

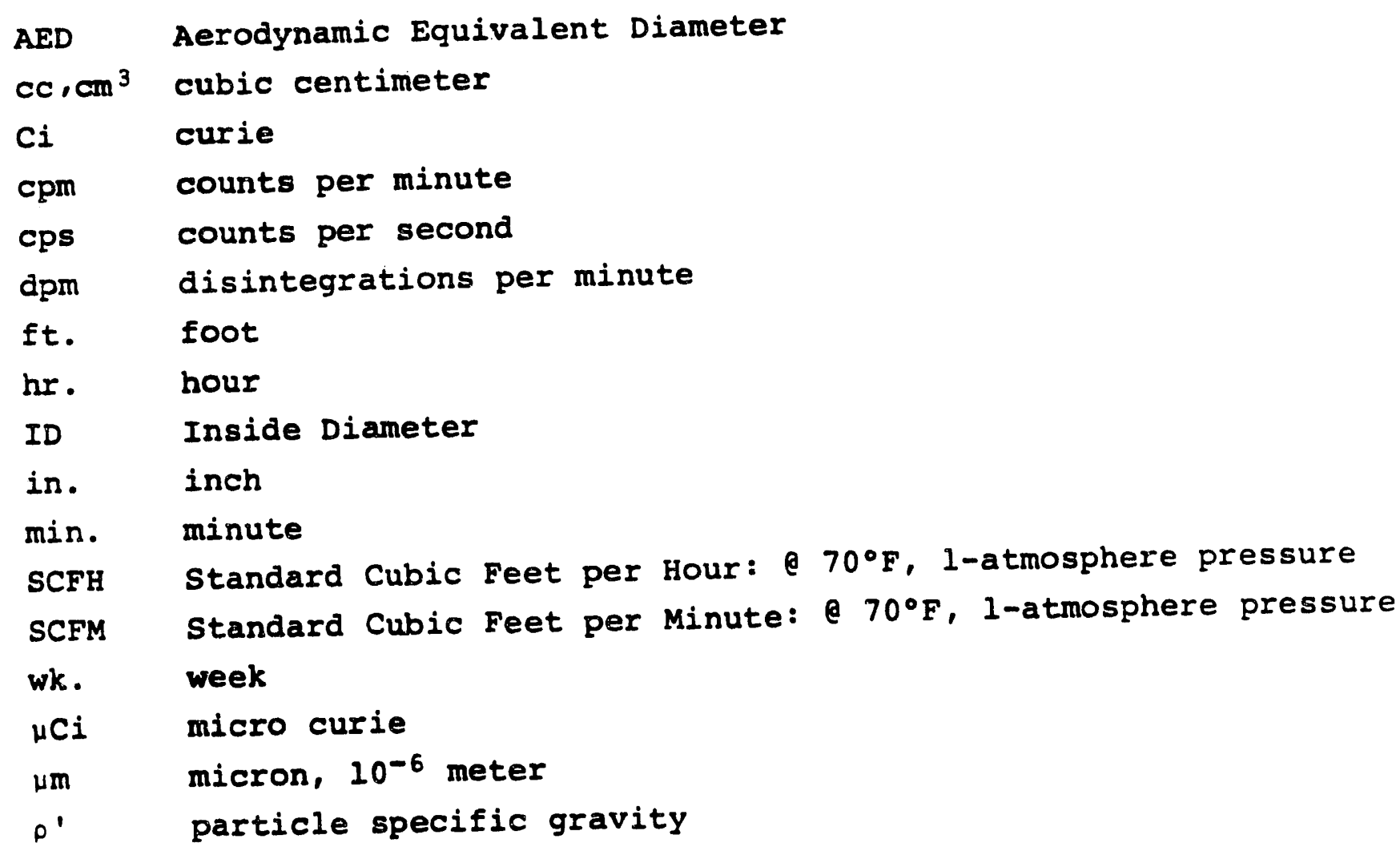




\section{REFERENCES}

[1] I.C. Schwendiman, G.E. Stegen, J. Mishima, and J.A. Glissmeyer. Interim Report: An Analysis of the Gaseous Effluent Sampling system - 225-B, waste Encapsulation and storage Facility, BNWL-B-408, Battelie-Northwest, Richland, Wash. (April, 1975).

[2] American National Standards - ANSI N13.1-1969, Guide to Sampling Airborne Radioactive Materials in Nuclear Facilities, American National Standards Institute, New York, New York (1969).

[3] ERDA Manual Chapter 0524, Appendix, Annex A, Table II.

[4] Byron Logman, Private Communications, ARHCO, January, 1976.

[5] ARHCO Document No. ARH-869, An Outline of Environmental Air Sample Analysis, Atlantic Richfield Hanford Co., Richland, Washington, (October 1968).

\section{DRAWINGS}

ARHCO ENGINEERING FILES

[6] H-2-33904, Stack Monitor - Air Sampler Assembly and Details.

[7] H-2-37441, K-3 Emergency Air Ejector System Piping \& Detials.

[8] H-2-66531, HVAC Air Flow Diagram.

[9] H-2-66653, Instrumentation $K-1$ and $K-3$ Filter Panels Arrangement and Details.

[10] H-2-66681, Instrument Engineering Diagram Building Exhaust System $\mathrm{R}-1$.

[11] H-2-66685, Instrumentation Stack Radiation Monitoring Arrangement and Details.

[12] H-2-66990, Engineering Flow Diagram -- Air Sampling.

[13] CVI File No. 14042, Effluent Stack and Related Items, 3-sheets Shelby Reinforced Plastics Corp., Pasco, Washington. 
APPENDIX A

Interim Radioactive Gaseous Effluent Samipling and Monitoring Criteria for Atlantic Richfield Hanford Company Facilities 
INTERIM RADIUACTIVE

GASEOUS EFFLUENT SAMPLING AND MONITORING CRITERIA

FOR ATLANTIC RICHFIELD HANFORD COMPANY FACILITIES

\section{INTRODUCTION}

To ensure that gaseous radioactive releases to the environment are kept as low as practicable, it is necessary to sample all of the radioactive or potentially radioactive gaseous effluent streams in the 200 Areas. Specific gaseous effluent streams that have the potential for release of large quantities of radioactive materials must also be monitored by radiation detection instrumentation.

The criteria listed below are intended to be used as guidelines to aid in the design of new systems or the upgrading of existing systems. It is highly desirable that new or upgraded systems be able to meet or nearly approach as many of the following criteria as is practicable.

SAMPLING CRITERIA

The term "sampling" applies to the extraction, transport and collection of a sample of the radionuclides present in the gaseous effluent stream on a collection media suitable for subsequent laboratory analysis. Gaseous effluent sampling systems shall:

1. extract in a 24-hour period a representative fraction of the effluent stream such that an activity release at least as low as the concentration guides given in ERDA Afperdi:: 0524, Anrax $\Lambda$, Tzble II can be measured with appropriate accuracy upon subsequent laboratory analysis.*

2. be designed, fabricated, and operated so that the particles extracted and transported to the collector will be representative to the degree that particles 19 micrometers and smaller in the sample collected will be at least 90 percent of the 10 micrometer and smaller particles in the same volume of a truly representative sample. At least 90 percent of the radioactive gases withdrawn shall be collected on the media selected or delivered to the activity sensing chamber in flow through monitors.

3. operate in a continuous mode, except for short periods when the sample collection media is being changed, whenever the facility is exhausting to the atmosphere.

4. extract samples of particles and gases that are a representative aliquot of the actual effluent stream.

* If one half of the Class I Action Level in ARH-222, ARHCO Emergency Procedure 1.9 (or the Emergency Procedure that governs gaseous discharges for the specific facility) is less than the Table II concentration guides, use one half of the Class I Action Level from the appropriate Emergency Procedure as the basis for this criterion. 
5. collect at least two samples, one of which will be designated and used exclusively as an inventory sample.

6. shall provide particulate and gaseous samples that have not been adversely affected by condensation of moisture.

7. be equipped with a vacuum system for sample extraction that his. the same number of back-up power systems as the exhaust fans of the facility. The vacuum system shall be provided with an alarm that is activated upon the loss of vacuum.

8. provide an inventory sample which is an accurate aliquot, within a factor of two, of the absolute radioactive materiais of the effluent stream. (Note: This statement relates only to the sample extraction and delivery capability, not to the accuracy of detection and measurement.)

9. provide inventory samples with less that 25 percent variation from the mean of several similar samplings at the 95 percent confidence level.

10. have at least an annual check to ensure that variation in effluent characteristics (particle size, mass activity concentrations, etc.) have not changed significantly.

\section{MONITORING CRITERIA}

The term "monitoring" applies to the use of radiation detection instrumentation to meusure tire amolint of radioactivity collected by lle cuilection nieúia. Gaseous effluent monitoring systems shall:

1. monitor the samples collected (except for the designated inventory sample) as detailed in items 1-10 under Sampling Criteria. The monitoring system shall be able to detect an activity release at least as low as one half that required for the Class I Action Level listed in ARH-222, ARHCO Emergency Procedure 1.9 (or the Emergency Procedure that governs gaseous discharges for the specific facility).

2. detect the radiation from radionuclides in the effluent stream with appropriate sensitivity for the radiation emitted.

3. operate in a continuous mode, except for short periods while samples are being changed, whenever the facility is exhausting to the atmosphere.

4. be equipped with the same number of back-up power systems as the exhaust fans of the facility.

5. incorporate a permanent recorder to document the level of radioactivity measured by the radiation detection instrument.

$11 / 14 / 75$

DJC:bac 
6. be provided with a "fail-safe" system that alarms when a malfunction occurs in the radiation detection instrument or upon loss of vacuum.

7. alarm at a pre-set "trip" point that is consistent with a Class II Actio Level as specified in ARH-222, ARHCO Emergency Procesiure 1.9 (ur the Emergency Procedure that governs gaseous discharges for the specific facility).

8. be able to detect a Class II Action Level as specified in ARH-222, ARHCO Emergency Procedure 1.9 (or the Emergency Procedure that governs gaseous discharges for the specific facility) in less than 24 hours.

9. alarm visually and audibly in a continuously occupied area for both the "fail-safe" alarm(s) and the emergency alarm(s).

10. be equipped with sufficient range to detect activity levels up to 100 times the Class II Action Level in ARH-222, ARHCO Emergency Procedure 1.9 (or the Emergency Procedure that governs gaseous discharges for the specific facility).

11. have the radiation detection instrumentation cal ibrated on at least a quarterly basis. 
APPENDIX B

ARHCO Emergency Procedure: 2.7 .7

WESF IOSs of Electrical Power 


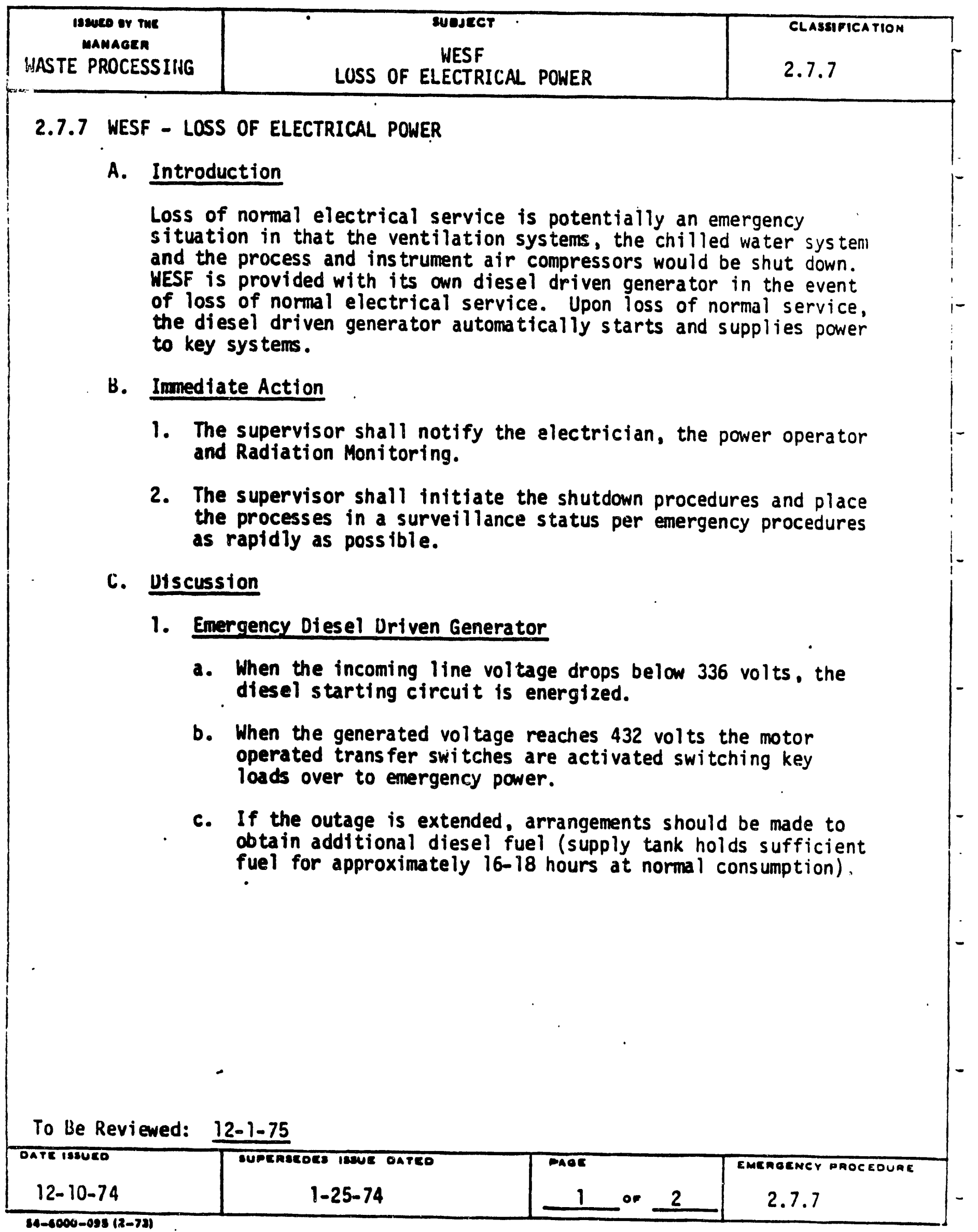


2. Systems on Emergency Power

a. MCC \#2 and \#3(225-B)

$K I$ and $K 3$ Supply and Exhaust $F$ ans

Storage Bas in Recirculation Pumps

Canyon Crane

Vacuum Pumps

Ins trument Power (Panel Board "C")

Cell Lighting a Emergency Lighting

TK-100 Pump

High Risk Cooling Water viverter Valve (Panel Board "A", 225-BU)

b. $M C C \# 4$ and $\# 5(225-B C)$

Air Compressors ( $\# 1$ and $\ddot{\pi} 2$ )

Either of the two water chiller refrigeration units

Cooling Tower Equipment associated with Fan K5-15-1

Chilled Water Recirculation Pumps

Condenser Water Pumps

225-BC Heaters (2) and Exhaust Fan

i. Return to i Normal Power

Emergency Diesel Uriven Generator

1. When line voltage exceeds 432 volts the transfer switches switch back to normal power.

2. The diesel-generator starting circuit is de-energized. The diesel-cenerator shuts down by a shutdown time delay relay.

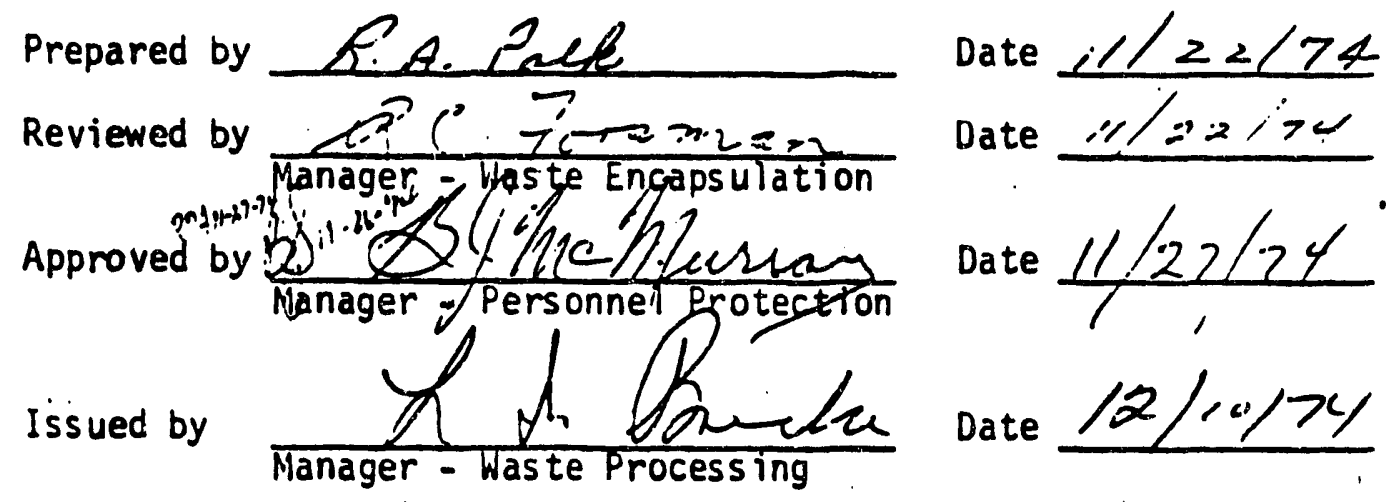

To Be Reviewed: $12-1-75$

\begin{tabular}{|c|c|c|c|c|}
\hline DATE ISSUEO & SUPEASEDES ISSUE DATEO & PAGE & & EMEACENCY PROCI.UUIII \\
\hline $12-10-74$ & $1-25-74$ & 2 & or & No. 2.7 .7 \\
\hline
\end{tabular}




\section{APPENDIX C}

ARHCO Emergency Procedure: 2.7.9

WESF Loss of Ventilation 


\begin{tabular}{|c|c|c|}
\hline $\begin{array}{c}\text { IsweO or me } \\
\text { MANAGER } \\
\text { WASTE PROCESSING }\end{array}$ & $\begin{array}{c}\text { BUEJECT } \\
\text { WESF }\end{array}$ & 2.7 .9 \\
\hline
\end{tabular}

\subsubsection{WESF - LOSS OF VEITTILATION}

A. Introduction

The WESF ventilation is accomplished by three supply systems and two exhaust systems to the main stack. Those areas having no potential for being contaminated have a separate supply and exhaust system. The two exhaust systems ( $K 1$ and $K 3$ ) exhaust the operating area and service area, the process cells and canyon respectively. In the event of fan or filter failure the $K 3$ system is provided with backup filters and the $\mathrm{kil}$ and $\mathrm{K} 3$ systems with exhaust fans in parallel with the on-line units. Further. the k3 system is provided with a steam jet for final exhauster backup.

B. Immediate Action

1. The supervisor shall notify the power operator of any ventilation irregularities.

2. In the event of a power outage the diesel driven generator will supply eniergency power to operate the $K I$ and $K 3$ exhaust fans and the $K I$ and $K 3$ supply fans.

3. In the event of a complete power outage and failure of emergency generator the building shall be immediately evacuated. The supervisor shall then verify that the emergency $K 3$ exhauster jet is operating.

C. Radiation and Contamination Control

1. The supervisor shall request radiation monitoring surveys of the operating areas and service areas.

2. The air monitors shall be frequently checked during periods of ventilation irregularities.

3. When necessary, personnel movemerit between ventilation zones shall be restricted for purposes of isolating potential or actual contamination.

To Be Reviewed: 12-1-75

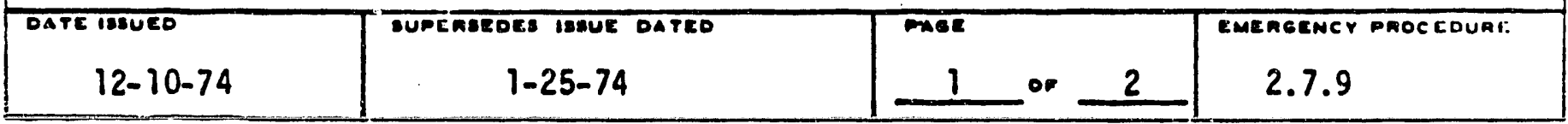


Armitic Richfield Hantord Compary

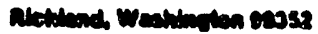

52

EMERGENCY PROCEDURE

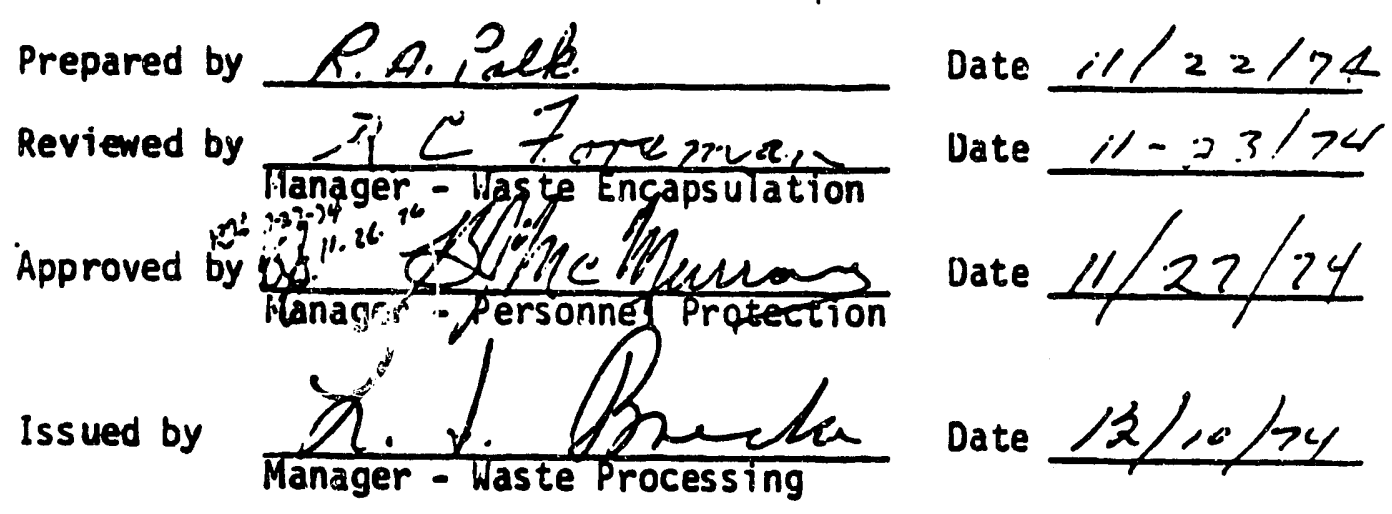

To Be Reviewed: 12-1-75

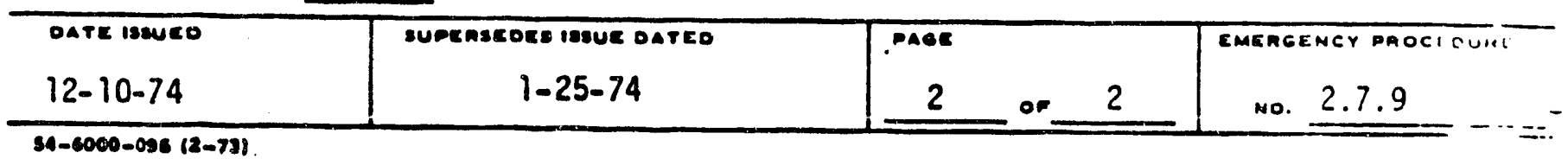




\section{APPENDIX D}

ARHCO Emergency Procedure: 2.7.12

WESF Radioactive Gaseous Discharge 
PERSONNEL PROTECTION

\begin{tabular}{|c|c|c|}
\hline $\begin{array}{c}\text { issueo or me } \\
\text { mamaeca } \\
\text { Waste Processing }\end{array}$ & SUDJECT & CLASSIFICATION \\
\hline
\end{tabular}

2.7.12 WESF - RADIOACTIVE GASEOUS DISCHARGE

A. Introduction

Ventilation exhaust gas from contaminated or potentially contaminated zones in the 225-B Building is exhausted to the atmosphere via the 70-foot high fiberglass reinforced plastic stack south of the building. Exhaust gas flows and fission product activity are continuously monitored at the stack and at the $K I$ and $K 3$ filters.

The potential exists for uncontrolled release of radioactivity whenever fission products are processed. In the event of a significant discharge the following instructions apply.

B. Signal

An alarm circuit is tripped by the continuous recorder for the sampler or samplers. The alarm causes an audible alarm and 1lluminates an alarm light on the supervisory panel board in the operating gallery.

C. Action Required

\section{Supervisor}

a. Upon receiving an alarm the responsible supervisor will immediately investigate to determine if the alarm is due to high radioactivity or due to instrument malfunction.

b. The supervisor will request replacements of the air sample and an immediate count of the sample by Radiation Monitoring.

c. The supervisor will notify his management if the alarm is found to be due to a radioactivity level that exceeds the levels described in Section $D$, below.

d. The supervisor will initiate an investigation to determine the source of radioactive emissions.

e. The supervisor will keep management informed throughout the progress of the investigations. He will consult $r i$ th management upon the course of action to resolve the problem and will prepare a written report of the investigation and findings.

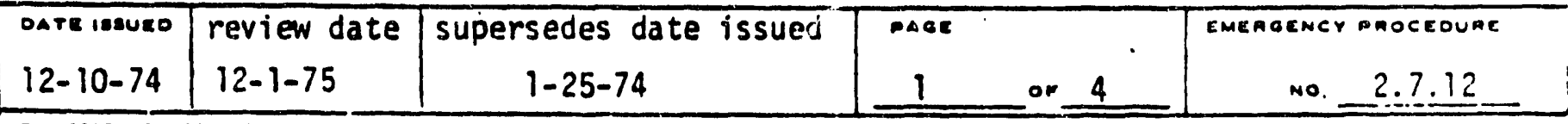


2. Radiation Monitoring Responsibilities

Radiation Monitoring will provide assistance by changing air samples, counting samples and evaluating data.

3. Engineering

Engineering will provide technical assistance as required during the investigation, isolation and resolution of probiems.

4. Management Responsibilities

a. Waste Processing Section management will provide guidance as required during the investigation, isolation and resolution of problems.

b. The Manager, Waste Processing Section w1ll determine when environmental discharges warrant defining the situation as being in the emergency category.

c. Waste Processing management will implement activities required of personnel under emergency conditions.

d. The Manager, Waste Processing will communicate all information to Departmental management required under emergency conditions.

D. Situation Definitions and Actions

1. Class I

\section{Definition}

Daily enviromental discharge exceeds ten percent of the release level values specified in the attached table and returns to less than 10 percent within 48 hours.

\section{Action}

Notify plant management who will in turn notify department managenent. Investigate to determine the cause. Document investigation and conclusions.

\section{Class II}

\section{Definition}

Daily environmental discharge exceeds ten percent of the release level values in the attached table for more than 48 hours.

\begin{tabular}{|c|c|c|c|c|c|}
\hline DATE ISSUED & review date & supersedes date issued & $\operatorname{AnCS}$ & & EMERGENCY PROCEOURI \\
\hline $12-10-74$ & $12-1-75$ & $1-25-74$ & -2 & or & No. 2.7 .1 \\
\hline
\end{tabular}


Action

Notify plant management who will in turn notify department and division management. Investigate to determine the cause. Document the investigation and conclusions.

3. Class III - An Emergency

Definition

Environmental discharge exceeds the release level value in the attached table.

\section{Action}

Notify plant management who will in turn notify department, division management and the U. S. Atomic Energy Commission.

Promp-ly investigate to determine the cause and corrective action.

4. Class IV - An Emergency

\section{Definition}

Environmental discharge that exceeds ten times the release level values in the attached table.

\section{Action}

Notify plant management immediately. They will in turn notify department and division management who will immediately notify the U. S. Atomic Energy Comission. Investigate promptly to determine the cause and corrective actions. If control cannot be imme-iately established or the discharge has exceeded 100 times the release level values, the facility shall be shut down. Document the investigation and conclusions.

Positive action will be taken to prevent recurrence.

Prepared by $Q 2 . M$. Pet $Q$

Reviewed by

Approved by

$$
\text { Subsection Manager }
$$

Issued by

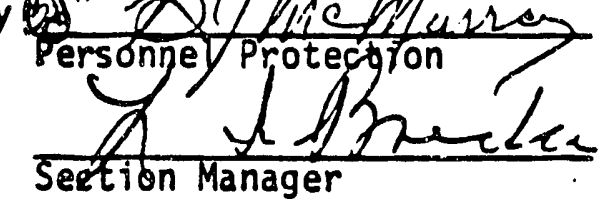

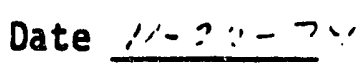

Date $1,-2 ?-7 \%$

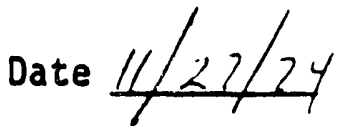

Date

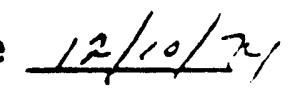

\begin{tabular}{|c|c|c|c|c|}
\hline DATE ISSUEO &  & süpersedes date tssüed & DAGE & EMERGENEY DROCEUUUAI \\
\hline $12-10-74$ & $12-1-75$ & $1-25-74$ & 3 & No. 2.7 .12 \\
\hline
\end{tabular}


Gaseous Wastes

References: ARH-220 - Radiation Protection Standards and Controls

ARH-2729- WESF Process Specifications and Standards

Gaseous radioactive wastes (mists or gases) shall be controlled so that the amounts released will be kept as small as practicable and should not average greater than the following amounts:

Constituent

${ }^{90} \mathrm{Sr}$

137 Cs

Total Beta
Weekly Discharge Limit

$<1 \times 10^{-3}$ curies/week

$<1 \times 10^{-2}$ curies/week

$<2 \times 10^{-2}$ curies/week

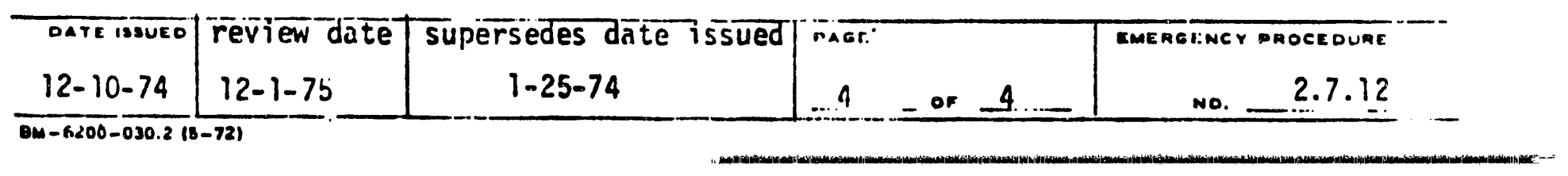



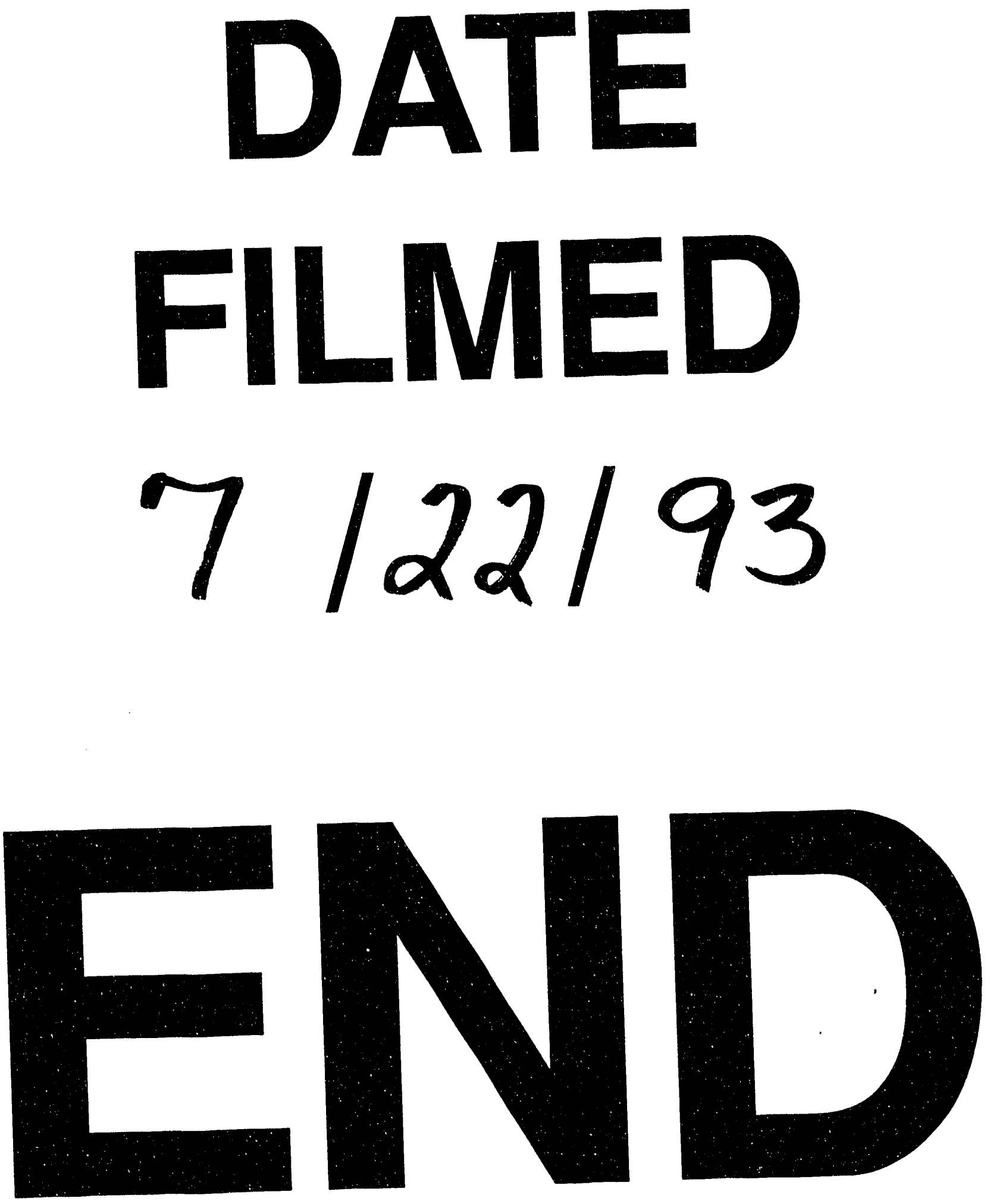
